\title{
Cell-type selective deletion of RSK2 reveals insights into altered signaling in \\ Coffin-Lowry Syndrome
}

Hu Zhu ${ }^{1}$, Ryan T. Strachan ${ }^{1}$, Daniel J. Urban ${ }^{1}$, Martilias S. Farrell ${ }^{1}$, Wesley K. Kroeze ${ }^{1}$, Justin G. English ${ }^{1}$, Reid H.J. Olsen ${ }^{1}$, and Bryan L. Roth ${ }^{1,2,3,4,5,6^{*}}$

1. Department of Pharmacology, School of Medicine, University of North Carolina at Chapel Hill, Chapel Hill, NC

2. Carolina Institute for Developmental Disabilities, University of North Carolina, Chapel Hill, NC, USA

3. Program in Neuroscience, University of North Carolina, Chapel Hill, NC, USA

4. Lineberger Comprehensive Cancer Center, University of North Carolina, Chapel Hill, NC, USA

5. Division of Chemical Biology and Medicinal Chemistry, School of Pharmacy, University of North Carolina, Chapel Hill, NC, USA

6. NIMH Psychoactive Drug Screening Program, University of North Carolina, Chapel Hill, NC, USA

*Corresponding author: Dr. Bryan L. Roth, Department of Pharmacology, UNC Chapel Hill Medical School, 4072 Genetic Medicine Building, 120 Mason Farm Rd., Chapel Hill, NC 27599. E-mail: bryan_roth@med.unc.edu

\begin{abstract}
Coffin-Lowry syndrome (CLS) is an X-linked syndromic form of mental retardation characterized by various skeletal dysmorphisms, moderate to severe mental retardation, and in
\end{abstract}


some cases, psychosis. CLS is caused by loss-of-function mutations of the p90 ribosomal S6 kinase 2 (RPS6KA3) gene encoding a growth factor-regulated serine/threonine kinase, ribosomal S6 kinase 2 (RSK2). We previously identified RSK2 as a novel interacting protein that tonically inhibits $5-\mathrm{HT}_{2 \mathrm{~A}}$ receptor signaling by phosphorylating Ser-314 within the third intracellular loop. To determine if RSK2 inhibits $5-\mathrm{HT}_{2 \mathrm{~A}}$ receptor signaling in vivo and whether disruption of RSK2 could lead to schizophrenia-like behaviors - as is seen in some CLS patients - we genetically disrupted the function of RSK2 either globally or selectively in forebrain pyramidal neurons in mice. Both global and forebrain-selective RSK2 deletion augmented the locomotor responses to the psychotomimetic drugs phencyclidine (PCP) and amphetamine (AMPH). Significantly, forebrain-selective deletion of RSK2 augmented 5- $\mathrm{HT}_{2} \mathrm{~A}$ receptor signaling as exemplified by enhanced 5-HT $2 \mathrm{~A}$-mediated c-fos activation and head-twitch response without altering the levels or distribution of $5-\mathrm{HT}_{2} \mathrm{~A}$ receptor protein. Thus, RSK2 modulates $5 \mathrm{HT}_{2 \mathrm{~A}}$ receptor function in vivo, and disruption of RSK2 leads to augmented psychostimulant-induced responses reminiscent of those seen in many animal models of schizophrenia. These findings strengthen the association between $5-\mathrm{HT}_{2 \mathrm{~A}}$ receptor dysfunction and psychosis, and provide a potential mechanism underlying the schizophrenia-like symptoms present in some CLS patients.

\section{Highlights:}

- Global and cell-type-specific RSK2 knock-out mice were assessed behaviorally and pharmacologically

- Augmentation of amphetamine and PCP locomotor responses were seen in both global and forebrain-specific RSK2 KO mice

- Augmentation of 5-HT2A serotonin receptor function but not number was also observed 
- These alterations reveal insights into mechanisms potentially responsible for behavioral sequlae of Coffin-Lowry Syndrome

Keywords: 5-HT2A serotonin; Coffin-Lowry Syndrome; GPCR; Scaffolding proteins

\section{INTRODUCTION: ${ }^{1}$}

Coffin-Lowry syndrome (CLS) is an $\mathrm{X}$ chromosome-linked mental retardation disorder characterized by growth defects, hypotonia, psychomotor retardation and distinct facial, hand

${ }^{1}$ Abbreviations: RSK2: growth factor-regulated serine/threonine kinase, ribosomal S6 kinase 2 ; MAPK: multifunctional effector of the mitogen-activated protein kinase; CLS: Coffin-Lowry Sydnrome. 
and skeletal malformations (A. Hanauer and I. D. Young, 2002). Individuals with CLS frequently display the symptoms of autism spectrum disorder as well as psychosis (U. Sivagamasundari et al., 1994). CLS is caused by a variety of heterogeneous loss-of-function mutations in the ribosomal protein S6 kinase, 90kDa, polypeptide 3 (RPS6KA3) gene, which maps to Xp22.2 (E. Trivier et al., 1996). Over 150 distinct mutations have been discovered, with most being unique to individual affected families (J. Delaunoy et al., 2001; J. P. Delaunoy et al., 2006; P. M. Pereira et al., 2010; A. Schneider et al., 2013). The RPS6KA3 gene encodes the growth factor-regulated serine/threonine kinase, ribosomal S6 kinase 2 (RSK2). Mutations of the RPS6KA3 gene lead to premature termination of translation and/or to loss of phosphotransferase activity of RSK2 (A. Hanauer and I. D. Young, 2002; P. M. Pereira et al., 2010). Global RSK2 knockout (KO) mice display profound growth retardation, progressive bone loss, memory deficits, and cognitive deficiencies (S. D. Dufresne et al., 2001; X. Yang et al., 2004; R. Poirier et al., 2007).

RSK2 is a member of the ribosomal S6 kinase family which includes RSK1-RSK4. The RSK2 protein contains two functional kinase domains: the N-terminal kinase domain belongs to the AGC (protein kinase A, G and C) family, and the C-terminal kinase domain belongs to the CAMK (calcium/calmodulin-dependent protein kinase) family. RSK2 is a multifunctional effector of the mitogen-activated protein kinase (MAPK) signaling pathway (J. Xing et al., 1996) and is phosphorylated and activated by extracellular signal-regulated kinase (ERK) in response to growth factors, polypeptide hormones and neurotransmitters. Upon activation, RSK2 can phosphorylate a variety of substrates both in the cytosol (e.g., Glycogen synthase kinase 3 beta (GSK3 $\beta)$, L1 cell adhesion molecule (L1CAM), Eukaryotic translation initiation factor 4b 
(eIF4B), BCL2-associated agonist of cell death (BAD) and SH3 and multiple ankyrin repeat domains (SHANK)) and in the nucleus (e.g., cAMP response element-binding protein (CREB), Estrogen receptor (ER), Nuclear hormone receptor 77 (Nur77), FBJ murine osteosarcoma viral oncogene homolog (c-fos) and Activating transcription factor 4 (ATF4)) to regulate cell proliferation, differentiation and survival (Y. Romeo et al., 2012).

Loss-of-function of RSK2 in humans leads to Coffin-Lowry syndrome, which includes behavioral characteristics of a schizophrenia-like psychosis in some individuals (R. A. Collacott et al., 1987; U. Sivagamasundari et al., 1994; A. G. Hunter, 2002). However, it is unknown how RSK2 mutations lead to this psychosis-like condition. In previous studies (D. J. Sheffler et al., 2006), we discovered that RSK2 exerts a tonic brake on the signaling of a variety of G proteincoupled receptors (e.g., P2Y-purinergic, PAR-1-thrombinergic, $\beta 1$-adrenergic, and bradykinin-B receptors). We also found that RSK2 directly interacts with the 5- $\mathrm{HT}_{2 \mathrm{~A}}$ receptor and phosphorylates intracellular loop 3 at the conserved Ser-314 to attenuate $5-\mathrm{HT}_{2} \mathrm{~A}$ receptor signaling (R. T. Strachan et al., 2009). Accordingly, we hypothesized that genetic deletion of the RSK2 gene may lead to an augmentation of $5-\mathrm{HT}_{2} \mathrm{~A}$ receptor signaling and induction of a psychosis-like behavior in mice. To test this hypothesis, here we used two mouse models: a global RSK2 KO mouse and a newly created conditional RSK2 KO mouse. We found that both global and forebrain-specific deletion of RSK2 augments 5-HT2A receptor signaling and some of the psychotomimetic actions of PCP and amphetamine. 


\subsection{MATERIALS AND METHODS:}

\subsection{Animals}

Mice were maintained in a 12-h light/dark cycle with unlimited access to water and laboratory chow. All procedures were conducted in strict compliance with the "Guide for the Care and Use of Laboratory Animals" (Institute of Laboratory Animal Resources, National Research Council, 1996 edition) and approved by the Institutional Animal Care and Use Committee of the University of North Carolina. RSK2 KO mice (C57BL/6J) were generated and provided by Dr. André Hanauer (Institute of Genetics, and Molecular and Cellular Biology, Illkirch, CEDEX, France) (R. Poirier et al., 2007).

\subsection{Creation of a conditional RSK2 KO mouse}

Briefly, a targeting vector for the mouse RSK2 gene was constructed. RSK2 exon 4 was flanked by loxP sites, and two positive selection markers flanked by flippase (Flp) recognition target sites FRT (NeoR, neomycin resistance) and F3 (PuroR, Puromycin resistance) were inserted into introns 3 and 4, respectively. The targeting vector was transfected into the TaconicArtemis C57BL/6N Tac ES cell line by Taconic Farms, and homologous recombinant clones were isolated using double positive selection markers. The targeted ES cells were injected into blastocysts to generate chimeras. Chimerism was measured by coat color contribution of ES cells to BALB/C host (black/white). Highly chimeric mice were bred with Flp-Deleter mice (Taconic Farms) to remove the selection markers. The conditional allele ( $\mathrm{RSK} 2^{\text {flox }}$ ) was confirmed by genotyping. The tail DNA was amplified by PCR with a primer pair directed against the third intron (forward primer, 5'- CCTTAAGTTACAACCCTAGCATCC -3'; reverse primer, 5'- 
TTCCTTTATTACAGCCAAGACTCC -3'), which generated a 525-bp amplicon in the conditional allele and a 353bp amplicon in the wild type allele. Mice carrying a conditional allele were then backcrossed to the C57 BL/6 mice for more than 10 generations.

To generate forebrain-selective RSK2 KO mice, homozygous male EMX1-Cre transgenic mice $\left(E m x 1^{\mathrm{tm} 1(\mathrm{cre}) \mathrm{Krj}}\right.$, Jackson Labs) were crossed with heterozygous female RSK2 $2^{\text {flox/+ }}$ mice. All offspring will contain Cre recombinase transgene and since the RSK2 gene is located on the X chromosome, half of the male offspring will contain $\mathrm{RSK} 2^{\text {flox }}$ allele and half will contain the WT allele. To detect the Cre recombinase transgene, PCR was carried out using the primers 5'GCGGTCTGGCAGTAAAAACTATC-3' and 5'-GTGAAACAGCATTGCTGTCACTT-3', which generated a 102-bp amplicon from the Cre-coding region.

\subsection{Quantitative reverse transcriptase-PCR}

EMX-RSK2 KO and littermate control mice were injected with the 5- $\mathrm{HT}_{2}$-selective agonist 2,5dimethoxy-4-iodoamphetamine (DOI, $0.5 \mathrm{mg} / \mathrm{kg}$, i.p.) and after $1 \mathrm{~h}$, mice were euthanized, and total RNA was immediately isolated from micro-dissected frontal cortex tissue using Trizol (Invitrogen, Carlsbad, CA, USA). $10 \mu \mathrm{g}$ of RNA was treated with DNAse (DNA-free, Ambion, Austin, TX, USA), and first strand complementary DNA was synthesized from $2 \mu \mathrm{g}$ of the DNase-treated RNA using the Superscript III RNase H Reverse Transcriptase kit (Invitrogen), with random hexamer primers (Invitrogen). Mouse c-Fos complementary DNA was amplified using Power SYBR Green PCR master mix (Applied Biosystems, Invitrogen, Carlsbad, CA, USA) in the 7500 Real-time PCR System (Applied Biosystems). The relative amount of c-Fos specific mRNA was determined by normalizing with $\beta$-actin mRNA present in the same samples and is expressed as fold above the saline-treated littermate control mice. The following gene- 
specific primers were used in PCR—mouse c-Fos: sense 5'-CAACACACAGGACTTTTGCG-3', anti-sense 5'-GGAGATAGCTGCTCTACTTTG-3'; mouse $\quad \beta$-actin: $\quad$ sense $\quad 5^{\prime}$ TGTTACCAACTGGGACGACA-3'; anti-sense 5'-CTGGGTCATCTTTTCACGGT-3'.

\subsection{Western blot}

Animals were sacrificed, and prefrontal cortex samples were harvested. The sample tissues were homogenized in ice-cold RIPA buffer (50mM Tris-Cl, pH 8.0;150mM NaCl, 0.1\% SDS, $1 \%$ NP-40, $0.5 \%$ Na-deoxycholate, plus protease inhibitor cocktail (50ml RIPA buffer/tablet, Roche)) and allowed to lyse on ice for $30 \mathrm{~min}$. After centrifuging at $25,000 \times \mathrm{g}$ for $30 \mathrm{~min}$ at $4{ }^{\circ} \mathrm{C}$, supernatants were transferred to a new tube. 20ug total protein were loaded and separated by SDS-PAGE gel, transferred to PVDF membranes, and probed with rabbit monoclonal anti-RSK2 antibody $\left(1: 1,000\right.$, Cell Signaling) at $4^{\circ} \mathrm{C}$ overnight. After three washes, the blot was probed with horseradish peroxidase-conjugated goat anti-rabbit $\operatorname{IgG}$ antibody (1:2,000, life technology) at room temperature for $1 \mathrm{hr}$. The blot was washed three times and incubated with chemiluminescent substrate (Thermo Scientific) and imaged in a Kodak Imager. After imaging, the blot was extensively washed and re-probed with mouse monoclonal anti- $\beta$-actin antibody $(1: 10,000$, Sigma).

\subsection{Immunohistochemistry}

Immunohistochemistry was performed as previously described (A. I. Abbas et al., 2009). Briefly, adult mice were anesthetized and perfused with $4 \%$ parafromaldehyde (PFA) in 1xPBS. Mouse brains were harvested, postfixed in 1xPBS/4\% PFA overnight, and then dehydrated in 1xPBS $130 \%$ sucrose until they sank. $40 \mu \mathrm{m}$ brain sections were cut and mounted onto poly-1-lysine coated microscope slides. To counterstain the neurons, NeuroTrace 530/615 (1:100, Invitrogen) 
was applied to slides and incubated at room temperature for 30min. After extensive washes, the sections were permeabilized with $1 \times \mathrm{PBS} / 0.4 \%$ Triton $\mathrm{X}-100$ for $1 \mathrm{hr}$, and then blocked with 1xPBS/0.4\% Triton X-100 solution containing 1\% bovine serum albumin and 5\% normal goat serum at room temperature for $1 \mathrm{hr}$. Primary antibodies diluted in the blocking solution were then applied to the slides and incubated at $4{ }^{\circ} \mathrm{C}$ overnight. The following primary antibodies were used: mouse monoclonal anti-RSK2 antibody (1:200, Abcam) and rabbit polyclonal anti-5HT2A antibody (1:200, Neuromics). Following the wash with 1xPBS/0.4\% Triton X-100, slides were incubated with either AlexaFluor 488 goat anti-mouse antibody or AlexaFluor 594 goat antirabbit antibody (1:250, Invitrogen) diluted in the blocking solution at room temperature for $1 \mathrm{hr}$. Fluorescent images were collected on a Nikon 80i Research Upright Microscope (Nikon, Tokyo, Japan) equipped with Surveyor Software with TurboScan (Objective Imaging, Kansasville, WI). Tiled images were collected with a Qimaging Retiga-EXi camera (Qimaging, Surrey, BC, Canada). The signal intensity was quantified using Image J software (NIH). Raw images were corrected by subtracting the average intensity value of the background. Three regions of interest (ROIs), 200 by 200 pixels, were randomly selected for layer $\mathrm{V}$ and peripheral layers; the mean intensity was then measured for each ROI, and these were averaged for each brain section.

\subsection{Head-twitch response}

Head-twitch response was tested as reported previously (J. A. Allen et al., 2011). Briefly, animals were transferred to the procedure room and acclimated to the new environment for at least 30min. Animals were injected intraperitoneally (i.p.) with various doses of DOI or vehicle and placed into the center of a Plexiglas cage for $20 \mathrm{~min}$, during which time head-twitch behavior was scored (5 min bins) by an experienced observer blind to genotype and drug 
treatment. Head-twitch behavior is defined as a rapid rotational jerk of the head, which is different from grooming or scratching behaviors (J. Gonzalez-Maeso et al., 2007).

\subsection{Open field test}

Exploration in a novel environment was assessed by a two hour trial in an open field (40 cm x 40 $\mathrm{cm} \times 30 \mathrm{~cm}$ ) crossed by a grid of photobeams (VersaMax system, AccuScan Instruments). Counts were taken of the number of photobeams broken during the trial in five-minute intervals, with separate measures for horizontal activity (total distance traveled), stereotypy activity (repeated breaking of the same set of photobeams), and vertical activity (rearing movements). For pharmacological studies, animals were injected IP with either MDL 100907 (0.2 or 0.5 $\mathrm{mg} / \mathrm{kg}$ ) or vehicle (0.9\% saline) and placed into the activity box. After 30min, animals were injected IP with PCP or AMPH $(6 \mathrm{mg} / \mathrm{kg})$ and immediately returned to the activity box for 90min. Activity was monitored during whole period.

\subsection{Elevated plus-maze test}

Mice were given one 5-min trial on a metal plus-maze, which had two closed arms with walls 20 $\mathrm{cm}$ in height, and two open arms. The maze was elevated $50 \mathrm{~cm}$ from the floor, and the arms were $30 \mathrm{~cm}$ long. Animals were placed on the center section $(8 \mathrm{~cm} \times 8 \mathrm{~cm})$, and allowed to freely explore the maze. Arm entries were defined as all four paws entering an arm. Entries and time in each arm were recorded during the trial by a blinded human observer via computer coding.

\subsection{Accelerating rotarod}


Subjects were tested for motor coordination and learning on an accelerating rotarod (Ugo Basile,

Stoelting Co., Wood Dale, IL). For the first test session, animals were given three trials, with 45 seconds between each trial. Two additional trials were given 48 hours later. Rpm (revolutions per minute) was set at an initial value of 3 , with a progressive increase to a maximum of $30 \mathrm{rpm}$ across five minutes (the maximum trial length). Measures were taken for latency to fall from the top of the rotating barrel in five minute test periods.

\subsection{Social approach test}

The three-chamber social approach test was designed to assess the sociability and the preference of social novelty of animals. All animal behaviors were monitored and analyzed by an automated tracking system (Noldus Ethovision). The test subject was first placed in the middle chamber and allowed to explore for ten minutes. After the habituation period, an unfamiliar C57BL/6J mouse (stranger 1) was placed in one of the side chambers enclosed in a small wire cage. An identical empty wire cage was placed in the opposite side of the chamber. The subject was then allowed to explore three chambers for a ten-minute session and the amount of time subject spent exploring the unfamiliar mouse or empty cage was recorded. At the end of the sociability test, each mouse was further tested for exploration of a new unfamiliar mouse (stranger 2) placed in the previously empty wire cage. Under these conditions the test mouse had a choice between the first, already-investigated mouse (stranger 1) and the novel unfamiliar mouse (stranger 2). The same measures were taken as with the sociability test.

\subsection{Morris water maze}

The Morris water maze task was described in our previous study (H. Zhu et al., 2014). Briefly, 
mice were given a visual cue test first to evaluate the visuo-motor abilities and the motivation of the animals. After the visual cue test, mice were trained in the hidden platform test as described previously. Each animal was given 4 trials per day, across 6 days, to learn the location of the submerged platform. The criterion for learning was an average latency of $15 \mathrm{sec}$ or less to locate the hidden platform. After meeting this criterion, mice were then tested for spatial memory during a $1 \mathrm{~min}$ trial in the pool with the platform removed. Spatial memory was evaluated by measuring the percent of time mice spent in the quadrant where the hidden platform was located.

\subsection{Fear conditioning}

Conditioned fear was evaluated using a Near-Infrared Video Fear Conditioning system (MED Associates, St. Albans, VT). In the training phase, mice received 3 pairings of a $30-\mathrm{sec}, 90 \mathrm{~dB}, 5$ $\mathrm{kHz}$ tone (conditioned stimulus, CS) and a 2-sec, $0.6 \mathrm{~mA}$ foot shock (unconditioned stimulus, US). Contextual memory was evaluated in the original training chamber 24 hours following the training phase, whereas cued memory was evaluated in a new chamber 48 hours following the training phase. Periods of freezing (no movement for $0.5 \mathrm{sec}$ ) were automatically measured by the image tracking software (Med Associates, St Albans, VT).

\subsection{Prepulse inhibition of startle response}

The acoustic startle test was used to evaluate reactivity to an auditory stimulus and sensorimotor gating as previously described (J. A. Allen et al., 2011). Mice were tested with a San Diego Instruments SR-Lab system. Briefly, mice were placed in a small Plexiglas cylinder within a larger, sound-attenuating chamber. The cylinder was seated upon a piezoelectric transducer, which allowed vibrations to be quantified and displayed on a computer. The chamber included a 
ceiling light, fan, and a loudspeaker for the acoustic stimuli. Background sound levels (70 dB) and calibration of the acoustic stimuli were confirmed with a digital sound level meter (San Diego Instruments). Each session consisted of 42 trials that began with a five-minute habituation period. There were 7 different types of trials: no-stimulus trials, trials with the acoustic startle stimulus (40 msec; $120 \mathrm{~dB}$ ) alone, and trials in which a prepulse stimulus (20 msec, either 74, 78 or $82 \mathrm{~dB}$ ) occurred $100 \mathrm{~ms}$ before the onset of the startle stimulus. Measurements were taken of the startle amplitude for each trial across a $65-\mathrm{msec}$ sampling window, and an overall analysis was performed for each subject's data for levels of prepulse inhibition at each prepulse sound level (calculated as 100 - [(response amplitude for prepulse stimulus and startle stimulus together / response amplitude for startle stimulus alone) x 100]. For pharmacological studies, animals were injected IP with vehicle (0.9\% saline) or MDL $100907(0.2$ or $0.5 \mathrm{mg} / \mathrm{kg})$ and returned to their home cage. After $30 \mathrm{~min}$, animals were injected IP with phencyclidine (4 or $6 \mathrm{mg} / \mathrm{kg}$ ) and immediately placed into the PPI apparatus.

\subsection{Receptor autoradiography}

5-HT $2 \mathrm{~A}$ receptor autoradiography was performed as previous reported (J. A. Allen et al., 2011). Briefly, brains were quickly removed, frozen on dry ice, and stored at $-80^{\circ} \mathrm{C}$ until processing. Coronal brain sections $(20 \mu \mathrm{m})$ (Bregma: $2.10 \mathrm{~mm}$ to Bregma $1.54 \mathrm{~mm}$ ) were cut on a cryostat, thaw-mounted onto slides (Fisher Scientific Tissue Path Superfrost Plus Gold Slides, \#15-18848), and vacuum desiccated at $4{ }^{\circ} \mathrm{C}$ overnight. Sections were incubated with ${ }^{125} \mathrm{I}-\mathrm{DOI}((+/-)-1-$ (2,5-dimethoxy-4-iodophenyl)-2-aminopropane HCL) (200 pM, 5-HT $2 \mathrm{~A} / 2 \mathrm{C}$ receptor agonist) for 1 hour at RT in standard binding buffer (50mM TrisHCl, $\mathrm{pH} 7.4 ; 10 \mathrm{mM} \mathrm{MgCl,} 0.1 \mathrm{mM}$ EDTA) to determine total binding. Ritanserin ( $1 \mathrm{uM} ; 5-\mathrm{HT}_{2 \mathrm{~A}} / 5-\mathrm{HT}_{2 \mathrm{C}}$ receptor antagonist) was added to the 
incubation mixture to determine non-specific binding. Sections were washed $(3 \times 10 \mathrm{~min})$ in icecold binding buffer (50 mM TrisHCl, $\mathrm{pH} 7.4$ ), rinsed in ice-cold water (to remove residual salts), then air-dried and exposed to hyperfilm (GE Healthscience) for one week. Films were developed and photographed with a digital camera system (Metaview). Image analysis was performed using ImageJ software to define regions of interest (ROI) in cortical layers 5 and 6 and this ROI was transposed onto the non-specific binding images. Average pixel intensities of the nonspecific ROI was subtracted from the total ROI to obtain qualitative specific binding data.

\subsection{Statistical Analysis}

For quantitation of immunoblots, immunostaining, mRNA expression and autoradiography, or other two-group comparisons, two-tailed unpaired t-tests were used to compare whether there is a significant difference between two groups. All behavioral data were analyzed by two-way ANOVA followed by Bonferroni post tests for comparing multiple groups. Comparisons were considered significant if the p-value was $<0.05$. 


\subsection{RESULTS:}

\subsection{Deletion of RSK2 augments psychotomimetic drug actions}

Deleting RSK2 in mice leads to a recapitulation of many of the symptoms of CLS patients, including deficits in body weight, adipose mass, glycogen metabolism, skeletal development, and learning and memory (S. D. Dufresne et al., 2001; K. El-Haschimi et al., 2003; X. Yang et al., 2004; R. Poirier et al., 2007). As some individuals with CLS exhibit a schizophrenia-like psychosis (R. A. Collacott et al., 1987; U. Sivagamasundari et al., 1994; A. G. Hunter, 2002), we evaluated two well-validated behavioral models that have been extensively used in various mouse models of psychosis and in testing antipsychotic drugs in mice: locomotion in the open field and prepulse inhibition of startle response (PPI) (S. B. Powell et al., 2009) after administration of the psychostimulants PCP and AMPH (D. C. Javitt and S. R. Zukin, 1991). Consistent with our previous work (A. I. Abbas et al., 2009; J. A. Allen et al., 2011), administration of $6 \mathrm{mg} / \mathrm{kg}$ PCP (Figure 1A) or AMPH (Figure 1C) induced hyperlocomotion in WT mice. Intriguingly, the hyperlocomotion induced by PCP (interaction of genotype and time, $\mathrm{F}(17,459)=2.35, \mathrm{p}=0.0018$; effect of genotype, $\mathrm{F}(1,459)=4.737, \mathrm{p}=0.0384$, two-way ANOVA) or AMPH (interaction of genotype and time, $\mathrm{F}(17,238)=3.899, \mathrm{p}<0.0001$; effect of genotype, $\mathrm{F}(1,238)=7.257, \mathrm{p}=0.0175$, two-way ANOVA) was significantly greater in global RSK2 KO mice compared with WT mice (Figure $1 \mathrm{~A}$ and $1 \mathrm{C}$ ). The selective $5-\mathrm{HT}_{2 \mathrm{~A}}$ receptor antagonists MDL 100,907 (MDL) (P. N. Yadav et al., 2010; J. A. Allen et al., 2011) and pimavanserin (P. N. Yadav et al., 2011; H. Y. Meltzer and B. L. Roth, 2013) have previously been demonstrated to attenuate PCP-induced hyperlocomotion in mice. As shown in Figure 1B, pretreatment with $0.5 \mathrm{mg} / \mathrm{kg}$ MDL significantly decreased PCP-induced locomotion in both genotypes. However, MDL was less effective in normalization of PCP-induced hyperlocomotion in RSK2 KO mice 
compared with WT mice at time point 35 minute and 40 minute (interaction of genotype and time, $\mathrm{F}(17,476)=2.913$, $\mathrm{p}<0.0001$; effect of genotype, $\mathrm{F}(1,476)=3.582, \mathrm{p}=0.0688$, two-way ANOVA). Pretreatment with $0.5 \mathrm{mg} / \mathrm{kg}$ MDL also decreased AMPH-induced locomotion in both genotypes. However, as was observed with PCP (Figure 1B), MDL was less effective in global RSK2 KO mice compared with WT mice (interaction of genotype and time, F(17,238)=3.43, $\mathrm{p}<0.0001$; effect of genotype, $\mathrm{F}(1,238)=7.155, \mathrm{p}=0.0181$, two-way ANOVA) (Figure 1D).

We next examined the effect of global RSK2 deletion on PCP-induced disruption of PPI (i.e., an inhibitory process wherein a preceding weak stimulus inhibits the response to a closely following strong stimulus), which is a well-established mouse model of schizophrenia-like circuitry dysfunction (D. L. Braff et al., 2001; G. S. Linn and D. C. Javitt, 2001). As shown in Figure 1E, baseline levels of PPI were comparable between WT and global RSK2 KO mice. PCP significantly disrupted PPI in both genotypes at all prepulse levels. Similar to locomotion studies (Figure 1B), we observed that MDL was effective at normalizing PCP-induced disruption of PPI in WT mice $(\mathrm{F}(1,40)=12.49, \mathrm{p}=0.0021$, two-way ANOVA), but not in RSK2 KO mice $(\mathrm{F}(1,42)=0.5965, \mathrm{p}=0.4485$, two-way ANOVA) particularly at 4 and $8 \mathrm{db}$ prepulse levels (Figure 1E). Taken together, locomotion and PPI studies support an enhancement of 5-HT2A-dependent signaling in global RSK2 KO mice.

\subsection{Generation of forebrain-specific RSK2 KO mice}

Given that the global RSK2 KO mouse has many non-neuronal phenotypes due to global RSK2 deletion, we undertook a more targeted approach by generating forebrain-specific conditional RSK2 KO mice. In these mice, exon 4 of the RSK2 gene was flanked by two LoxP sites that are 
removed by Cre recombinase, leading to a frameshift and premature termination of translation in exon 5. The resulting truncated protein contains only the first 81 amino acids of the RSK2 protein and lacks the kinase domain (Figure 2A). To selectively disrupt the RSK2 gene in the forebrain, we crossed heterozygous female conditional RSK2 mice (RSK2 ${ }^{\text {flox/+ }}$ ) with homozygous male EMX1-Cre mice $\left(\mathrm{EMX}^{\mathrm{Cre} / \mathrm{Cre}}\right)$ selectively expressing Cre recombinase in the cortex, hippocampus and olfactory bulb (T. Iwasato et al., 2000). As the RSK2 gene is X-linked, male offspring were either $\mathrm{EMX}^{\mathrm{Cre} /+} \mathrm{RSK}^{+}$or $\mathrm{EMX}^{\mathrm{Cre} /+} \mathrm{RSK}^{\text {flox }}$ (Figure 2B), with the $\mathrm{EMX}^{\mathrm{Cre} /+} \mathrm{RSK}^{\text {flox }}$ male mice possessing forebrain disruption of the RSK2 gene (hereafter referred to as EMX-RSK2 $\mathrm{KO}$ mice). Littermate $\mathrm{EMX}^{\mathrm{Cre} /+} \mathrm{RSK} 2^{+}$male mice served as controls in all studies.

To confirm forebrain-specific disruption of RSK2, we analyzed RSK2 protein expression using Western blot and immunofluorescence microscopy. Western blot results showed that there was a single $\sim 90 \mathrm{kDa}$ band of RSK2 protein in conditional RSK2 mice and EMX ${ }^{\mathrm{Cre} /}{ }^{+} \mathrm{RSK} 2{ }^{+}$control mice, but only a weak band was present in the EMX-RSK2 KO mice (Figure 2C). Immunohistochemistry with the neuron-specific stain NeuroTrace showed that RSK2 was not expressed in cortical (CTX) and hippocampal (HPC) neurons of EMX-RSK2 KO mice (Figure 2D), although expression was retained in thalamic neurons (Thal) lacking Cre recombinase (Figure 2D). In contrast, RSK2 was expressed in the neurons of all three brain regions in control mice (Figure 2E). Taken together, we generated EMX-RSK2 KO mice with forebrain-specific disruption of RSK2.

\subsection{EMX-RSK2 KO mice exhibit decreased sensitivity to 5-HT2A antagonism}


To determine whether forebrain-specific deletion of RSK2 leads to any intrinsic basal behavioral changes, animals were subjected to a battery of neurobehavioral tests in their naïve state. EMXRSK2 KO mice showed normal growth, body weight, and mating behavior, unlike global RSK2 $\mathrm{KO}$ mice that have been reported to display decreases in growth and weight gain (X. Yang et al., 2004). Additionally, basal locomotion, anxiety, motor coordination, sociability, and learning and memory were comparable between the $\mathrm{KO}$ mice and littermate control mice, as demonstrated in open-field, elevated plus maze, accelerating rotarod, social approach, fear conditioning and Morris water maze (Figure $3 \mathrm{~A}$ to $3 \mathrm{G}$ ). Together, these data show no baseline behavioral changes after disruption of RKS2 in the forebrain, distinct from results obtained by others with global RSK2 KO mice.

We next determined whether forebrain-specific RSK2 KO mice exhibit an augmented response to the psychotomimetic drugs PCP and AMPH. As seen in global RSK2 KO mice (Figure 1), PCP or AMPH administration induced hyperlocomotion in both control and EMX-RSK2 KO mice (Figure 4A and C). We observed no significant difference in PCP-induced hyperlocomotion between genotypes (interaction of genotype and time, $F(17,340)=0.9219, p=0.5482$; effect of genotype, $\mathrm{F}(1,340)=0.4912$, $\mathrm{p}=0.4915$, two-way ANOVA) (Figure 4A); however, we observed a significant increase in AMPH-induced hyperlocomotion in EMX-RSK2 KO mice (interaction of genotype and time, $\mathrm{F}(17,187)=5.725$, $\mathrm{p}<0.0001$; effect of genotype, $\mathrm{F}(1,187)=11.63$, $\mathrm{p}=0.0058$, two-way ANOVA) (Figure 4C). Next, we evaluated whether the PCP- or AMPH-induced hyperlocomotion in EMX-RSK2 KO mice could be effectively normalized by MDL. Injection of $0.2 \mathrm{mg} / \mathrm{kg}$ MDL 30min before PCP or AMPH administration significantly decreased PCP- and AMPH-induced locomotion in both genotypes (Figure 4B and D). However, as with the global 
RSK2 KO mice, MDL was less effective in EMX-RSK2 KO mice compared to littermate control mice (PCP- interaction of genotype and time, $F(17,340)=4.283, p<0.0001$; effect of genotype, $\mathrm{F}(1,340)=5.379, \mathrm{p}=0.0311$, two-way ANOVA) $(\mathrm{AMPH}$ - interaction of genotype and time, $\mathrm{F}(17,170)=4.591, \mathrm{p}<0.0001$; effect of genotype, $\mathrm{F}(1,170)=10.09, \mathrm{p}=0.0099$, two-way ANOVA) (Figure 4B and 4D).

We next determined if forebrain-specific deletion of RSK2 decreased the ability of the 5-HT2A antagonist MDL to normalize PCP-induced disruption of PPI as seen with the global RSK2 KO mice. As shown in Figure 4E, EMX-RSK2 KO mice exhibited both baseline and PCP-induced changes in PPI that were comparable to control mice. Injection of MDL $(0.2$ or $0.5 \mathrm{mg} / \mathrm{kg}) 30 \mathrm{~min}$ before PCP $(6 \mathrm{mg} / \mathrm{kg})$ administration normalized PCP-induced disruption of PPI in control mice $(\mathrm{F}(2,66)=4.818, \mathrm{p}=0.0146$, two-way ANOVA $)$; whereas it was not effective in EMX-RSK2 KO mice $(\mathrm{F}(2,84)=0.297, \mathrm{p}=0.7446$, two-way ANOVA) (Figure 4F). Similar to our observations with global RSK2 KO mice (Figure 1E), 5- $\mathrm{HT}_{2 \mathrm{~A}}$ blockade was less effective at normalizing the psychotomimetic effects of PCP.

\subsection{5-HT2A signaling is augmented in EMX-RSK2 KO mice}

Our previous studies (D. J. Sheffler et al., 2006; R. T. Strachan et al., 2009; R. T. Strachan et al., 2010a; R. T. Strachan et al., 2010b) demonstrated that RSK2 exerts a tonic brake on 5-HT2A signaling pathway in fibroblasts in vitro, though no data was available regarding the actions in neurons. To test this in vivo in forebrain neurons, we evaluated neuronal signaling and behavioral activity in EMX-RSK2 $\mathrm{KO}$ mice following administration of the 5-HT2A/2C receptor agonist DOI. DOI has been shown to selectively induce the expression of the immediate early 
response gene c-fos in the mouse cortex (J. L. Scruggs et al., 2000; A. I. Abbas et al., 2009), which is a marker of neuronal activation. Following $1 \mathrm{mg} / \mathrm{kg}$ DOI administration, both genotypes showed DOI-induced c-fos activation in the somatosensory cortex (SSC, Figure 5A) as demonstrated by immunohistochemistry with anti-c-fos antibody (Figure 5B). Notably, DOIinduced c-fos activation in EMX-RSK2 $\mathrm{KO}$ mice was significantly increased compared to littermate control mice (interaction of genotype and drug, $F(1,24)=5.993$, $p=0.022$, effect of genotype, $\mathrm{F}(1,24)=6.013, \mathrm{p}=0.0218$, two-way ANOVA) (Figure 5C). The augmented DOIinduced c-fos activation was also confirmed by analyzing c-fos gene expression via quantitative polymerase chain reaction (qPCR). We observed an increase of DOI-induced c-fos activation in both genotypes, with the level of c-fos mRNA induced by DOI in EMX-RSK2 KO mice significantly greater than in control mice (interaction of genotype and drug, $F(1,32)=4.922$, $\mathrm{p}=0.0337$, effect of genotype, $\mathrm{F}(1,32)=4.538, \mathrm{p}=0.0409$, two-way ANOVA) (Figure 5D). Thus, forebrain-specific disruption of the RSK2 gene augments 5- $\mathrm{HT}_{2 \mathrm{~A}}$ signaling in vivo.

Next, we tested whether increased 5- $\mathrm{HT}_{2 \mathrm{~A}}$ function in EMX-RSK2 $\mathrm{KO}$ mice leads to an increased head twitch response (HTR) in animals. The HTR is a reliable and extensively validated behavioral readout for 5-HT2A agonism ( J. A. Allen et al., 2011) and has been shown to be elevated in PKC $\gamma \mathrm{KO}$ mice (B. J. Bowers et al., 2006). Following DOI (0, 0.5, $1.0 \mathrm{mg} / \mathrm{kg}$ ) administration, both genotypes showed a dose-dependent increase in HTR over a 20 min period (Figure 5E). Notably, the HTR was significantly greater in EMX-RKS2 KO mice compared to littermate control mice (interaction of genotype and dose, $\mathrm{F}(2,36)=3.613, \mathrm{p}=0.0372$, effect of genotype, $\mathrm{F}(1,36)=9.827, \mathrm{p}=0.0057$, two-way ANOVA) (Figure 5E). Since DOI is a 5-HT2A receptor partial agonist, we also treated mice with the full agonist 5-hydroxytryptophan (5-HTP) 
to fully activate this signaling pathway. Following 5-HTP $(0,50,100,200 \mathrm{mg} / \mathrm{kg})$ administration, the HTR was increased in both genotypes (Figure 5F). Similar to DOI, we observed that 5-HTP (100 and $200 \mathrm{mg} / \mathrm{kg}$ ) elicited a significantly greater HTR in EMX-RSK2 KO mice compared to the control mice (interaction of genotype and dose, $\mathrm{F}(3,24)=4.582$, $\mathrm{p}=0.0113$, effect of genotype, $\mathrm{F}(1,24)=19.57, \mathrm{p}=0.0022$, two-way ANOVA) (Figure 5F). Taken together, these results demonstrate that forebrain-specific RKS2 disruption potentiates $5-\mathrm{HT}_{2 \mathrm{~A}}$ function in vivo.

\subsection{EMX-RSK2 KO mice show no alteration in 5-HT2A receptor expression}

We next quantified 5-HT2A receptor expression via receptor autoradiography $\left({ }^{125} \mathrm{I}-\mathrm{DOI}\right.$ binding) and immunofluorescence microscopy to determine if altered receptor expression could account for the increased signaling in EMX-RSK2 KO mice. As shown in Figure 6A for both genotypes, we observed a high density of ${ }^{125}$ I-DOI labeling in layer $\mathrm{V}$ of the cerebral cortex which is known to contain high levels of 5-HT2A receptors (A. Pazos et al., 1985; J. F. Lopez-Gimenez et al., 1997). Quantitation revealed no significant difference between genotypes $(t(8)=0.2448$, $\mathrm{p}=0.8128$, unpaired t-test) (Figure 6C) and complete displacement by ritanserin--a 5-HT $2 \mathrm{~A} / 5$ $\mathrm{HT}_{2 \mathrm{C}}$ selective antagonist--confirmed the specificity of ${ }^{125} \mathrm{I}-\mathrm{DOI}$ binding. The expression of 5$\mathrm{HT}_{2 \mathrm{~A}}$ receptors in frontal cortex was further confirmed by immunostaining with a selective and previously validated 5-HT $2 \mathrm{~A}$ receptor antibody (P. N. Yadav et al., 2011). We observed an overall diffuse laminar staining in the cerebral cortex and characteristic intensive band staining in the apical dendritic trunk and secondary branches of layer V pyramidal cells (Figure 6B). In agreement with the ${ }^{125}$ I-DOI labeling, no significant difference was observed in the intensity of layer $\mathrm{V}$ and peripheral layer staining between EMX-RSK2 KO mice and littermate control mice 
$(\mathrm{F}(1,8)=1.147, \mathrm{p}=0.3153$, two-way ANOVA) (Figure 6D). Taken together, our results demonstrate that augmented 5- $\mathrm{HT}_{2 \mathrm{~A}}$ receptor signaling in EMX-RSK2 $\mathrm{KO}$ mice was not due to altered $5-\mathrm{HT}_{2 \mathrm{~A}}$ receptor expression in the forebrain. 


\subsection{DISCUSSION:}

The main findings of this paper are that (1) RSK2 exerts a tonic brake on 5-HT2A signaling in vivo, and (2) that genetic deletion of RSK2 augments some of the psychotomimetic actions of amphetamine and PCP. Importantly, for these studies we generated a conditional RSK2 KO mouse to demonstrate that these behavioral effects can be attributed to selective deletion of RSK2 from the forebrain. These results provide compelling support for the hypothesis that RSK2 modulates 5- $\mathrm{HT}_{2 \mathrm{~A}}$ signaling in vivo, dysregulation of which augments psychotomimetic drug actions.

As part of a large and ongoing effort to identify novel regulators of $5-\mathrm{HT}_{2 \mathrm{~A}}$ receptor signaling pathways, we identified RSK2 as a novel interacting protein that directly phosphorylates Ser-314 in the receptor third intracellular loop to decrease its signaling (D. J. Sheffler et al., 2006) (R. T. Strachan et al., 2009). Ultimately, it was revealed that RSK2 differentially regulates 5-HT2A agonist signaling (R. T. Strachan et al., 2009; R. T. Strachan et al., 2010b) and that RSK2 is required for receptor tyrosine kinase (RTK)-mediated desensitization of 5-HT2A receptors (R.T Strachan et al. 2010 Biochemistry). Consistent with these findings in cultured cells, we provide the first compelling evidence that RSK2 modulates 5- $\mathrm{HT}_{2 \mathrm{~A}}$ signaling in vivo. First, genetic deletion of RSK2 leads to an augmentation of $5-\mathrm{HT}_{2 \mathrm{~A}}$ receptor signaling without altering apparent receptor expression. Second, genetic deletion of RSK2 increases psychostimulantdriven psychotomimetic responses (i.e., PCP- or AMPH-induced hyperlocomotion and disruption of PPI) that are incompletely blocked by the 5-HT2A-specific antagonist MDL100907, which we attribute to increased responsiveness of 5- $\mathrm{HT}_{2 \mathrm{~A}}$ receptors (discussed below). However, it is possible that mechanisms outside of the $5-\mathrm{HT}_{2} \mathrm{~A}$ receptor account for this MDL-insensitivity. 
For instance, RSK2 deletion could alter the activity of additional receptor systems that augment psychostimulant responses given that RSK2 regulates the activity of other GPCRs (P2Ypurinergic, PAR-1-thrombinergic, $\beta 1$-adrenergic, and bradykinin-B receptors) (D. J. Sheffler et al., 2006). Moreover, Pereira et al. have shown dopaminergic dysregulation in the global RSK2 knockout mouse model (P. Marques Pereira et al., 2008). It is also possible that defects in neuronal growth due to impaired RSK2-dependent PLD1 activity contribute to the increased responsiveness of EMX-RSK2 KO mice to psychostimulants (M. R. Ammar et al., 2013), although the behavioral similarities between WT mice and forebrain deleted RSK2 mice argue against this possibility. More generally, our observation that $5-\mathrm{HT}_{2 \mathrm{~A}}$ receptor dysregulation is pro-psychotic and renders antagonists less effective is consistent with other in vivo studies in which 5-HT2A receptor interacting proteins were deleted (e.g., Cav1 and PSD-95 KO mice) (A. I. Abbas et al., 2009; J. A. Allen et al., 2011).

In the present study, we used multiple pharmacological approaches to evaluate $5-\mathrm{HT}_{2 \mathrm{~A}}$ receptor signaling in RSK2 mutant mice. In the first approach, we used the 5- $\mathrm{HT}_{2} \mathrm{~A}$ receptor selective antagonist MDL 100907 to block PCP- and AMPH-induced locomotion, which is typically used to evaluate 5-HT2A signaling in vivo. In a second approach, we used the potent hallucinogen DOI to activate 5-HT2A receptors in c-fos and HTR studies. Although DOI can activate both 5-HT2A and 5-HT $2 \mathrm{C}$ receptors in vitro, several lines of evidence support the role of 5- $\mathrm{HT}_{2 \mathrm{~A}}$ receptors, and not $5-\mathrm{HT}_{2 \mathrm{C}}$ receptors, in mediating the activation of $\mathrm{c}$-fos in the cortex and behavioral responses in animals. First, c-fos is primarily induced in cortical neurons expressing $5-\mathrm{HT}_{2 \mathrm{~A}}$ receptors (J. Gonzalez-Maeso et al., 2007). Second, pretreatment with the selective 5-HT2A antagonist MDL 100,907 completely blocks DOI-induced c-fos expression, whereas pretreatment with the 5- $\mathrm{HT}_{2 \mathrm{C}}$ 
antagonist SB 206553 fails to reduce DOI-induced c-fos expression (J. L. Scruggs et al., 2000). Third, DOI and other hallucinogens do not induce c-fos expression and HTR behavior in 5-HT2A KO mice (Gonzales-2007; Keiser et al, 2007), and Emx-Cre mediated restoration of 5-HT2A receptor expression is sufficient to rescue the signaling and behavioral response (J. GonzalezMaeso et al., 2007). The finding that RSK2 mutant mice are more sensitive to the psychotomimetic effects of PCP is interesting in light of the observation of aschizophrenia-like psychosis seen in some CLS patients.

In summary, our in vivo data are consistent with the hypothesis that RSK2 tonically inhibits 5$\mathrm{HT}_{2 \mathrm{~A}}$ receptor signaling In this paradigm, genetic disruption of RSK2 augments 5- $\mathrm{HT}_{2 \mathrm{~A}}$ receptor signaling and associated psychotic behaviors, suggesting that augmented $5-\mathrm{HT}_{2 \mathrm{~A}}$ receptor signaling is pro-psychotic and may contribute to the schizophrenia-like psychosis in some CLS patients. More generally, given the demonstrated clinical efficacy of antagonists with high affinity for 5-HT2A receptors (B. L. Roth and Z. Xia, 2004; J. Besnard et al., 2012; H. Y. Meltzer and B. L. Roth, 2013), our findings suggest that RSK2 mutations, or mutations in other regulatory proteins, could alter the therapeutic efficacy of antipsychotic drugs in the clinic. 


\subsection{REFERENCES}

Abbas Al, Yadav PN, Yao WD, Arbuckle MI, Grant SG, Caron MG, Roth BL (2009) PSD-95 is essential for hallucinogen and atypical antipsychotic drug actions at serotonin receptors. J Neurosci 29:71247136.

Allen JA, Yadav PN, Setola V, Farrell M, Roth BL (2011) Schizophrenia risk gene CAV1 is both propsychotic and required for atypical antipsychotic drug actions in vivo. Transl Psychiatry 1:e33.

Ammar MR, Humeau Y, Hanauer A, Nieswandt B, Bader MF, Vitale N (2013) The Coffin-Lowry syndromeassociated protein RSK2 regulates neurite outgrowth through phosphorylation of phospholipase D1 (PLD1) and synthesis of phosphatidic acid. J Neurosci 33:19470-19479.

Besnard J et al. (2012) Automated design of ligands to polypharmacological profiles. Nature 492:215220.

Bowers BJ, Miyamoto-Ditmon J, Wehner JM (2006) Regulation of 5-HT2A/C receptors and DOI-induced behaviors by protein kinase Cgamma. Pharmacol Biochem Behav 85:441-447.

Braff DL, Geyer MA, Light GA, Sprock J, Perry W, Cadenhead KS, Swerdlow NR (2001) Impact of prepulse characteristics on the detection of sensorimotor gating deficits in schizophrenia. Schizophr Res 49:171-178.

Collacott RA, Warrington JS, Young ID (1987) Coffin-Lowry syndrome and schizophrenia: a family report. J Ment Defic Res 31 ( Pt 2):199-207.

Delaunoy J, Abidi F, Zeniou M, Jacquot S, Merienne K, Pannetier S, Schmitt M, Schwartz C, Hanauer A (2001) Mutations in the X-linked RSK2 gene (RPS6KA3) in patients with Coffin-Lowry syndrome. Hum Mutat 17:103-116.

Delaunoy JP, Dubos A, Marques Pereira P, Hanauer A (2006) Identification of novel mutations in the RSK2 gene (RPS6KA3) in patients with Coffin-Lowry syndrome. Clin Genet 70:161-166.

Dufresne SD, Bjorbaek C, El-Haschimi K, Zhao Y, Aschenbach WG, Moller DE, Goodyear L (2001) Altered extracellular signal-regulated kinase signaling and glycogen metabolism in skeletal muscle from p90 ribosomal $\mathrm{S6}$ kinase 2 knockout mice. Mol Cell Biol 21:81-87.

El-Haschimi K, Dufresne SD, Hirshman MF, Flier JS, Goodyear L, Bjorbaek C (2003) Insulin resistance and lipodystrophy in mice lacking ribosomal $S 6$ kinase 2. Diabetes 52:1340-1346.

Geyer MA, Krebs-Thomson K, Braff DL, Swerdlow NR (2001) Pharmacological studies of prepulse inhibition models of sensorimotor gating deficits in schizophrenia: a decade in review. Psychopharmacology (Berl) 156:117-154.

Gonzalez-Maeso J, Weisstaub NV, Zhou M, Chan P, Ivic L, Ang R, Lira A, Bradley-Moore M, Ge Y, Zhou Q, Sealfon SC, Gingrich JA (2007) Hallucinogens recruit specific cortical 5-HT(2A) receptor-mediated signaling pathways to affect behavior. Neuron 53:439-452.

Hanauer A, Young ID (2002) Coffin-Lowry syndrome: clinical and molecular features. J Med Genet 39:705-713.

Homayoun H, Moghaddam B (2007) NMDA receptor hypofunction produces opposite effects on prefrontal cortex interneurons and pyramidal neurons. J Neurosci 27:11496-11500.

Hunter AG (2002) Coffin-Lowry syndrome: a 20-year follow-up and review of long-term outcomes. Am J Med Genet 111:345-355.

Iwasato T, Datwani A, Wolf AM, Nishiyama H, Taguchi Y, Tonegawa S, Knopfel T, Erzurumlu RS, Itohara S (2000) Cortex-restricted disruption of NMDAR1 impairs neuronal patterns in the barrel cortex. Nature 406:726-731.

Jakab RL, Goldman-Rakic PS (1998) 5-Hydroxytryptamine2A serotonin receptors in the primate cerebral cortex: possible site of action of hallucinogenic and antipsychotic drugs in pyramidal cell apical dendrites. Proc Natl Acad Sci U S A 95:735-740.

Javitt DC, Zukin SR (1991) Recent advances in the phencyclidine model of schizophrenia. Am J Psychiatry 
148:1301-1308.

Linn GS, Javitt DC (2001) Phencyclidine (PCP)-induced deficits of prepulse inhibition in monkeys. Neuroreport 12:117-120.

Lopez-Gimenez JF, Mengod G, Palacios JM, Vilaro MT (1997) Selective visualization of rat brain 5-HT2A receptors by autoradiography with [3H]MDL 100,907. Naunyn Schmiedebergs Arch Pharmacol 356:446-454.

Marek GJ, Wright RA, Gewirtz JC, Schoepp DD (2001) A major role for thalamocortical afferents in serotonergic hallucinogen receptor function in the rat neocortex. Neuroscience 105:379-392.

Marques Pereira P, Gruss M, Braun K, Foos N, Pannetier S, Hanauer A (2008) Dopaminergic system dysregulation in the mrsk2_KO mouse, an animal model of the Coffin-Lowry syndrome. J Neurochem 107:1325-1334.

Meltzer HY, Roth BL (2013) Lorcaserin and pimavanserin: emerging selectivity of serotonin receptor subtype-targeted drugs. J Clin Invest 123:4986-4991.

Pazos A, Cortes R, Palacios JM (1985) Quantitative autoradiographic mapping of serotonin receptors in the rat brain. II. Serotonin-2 receptors. Brain Res 346:231-249.

Pereira PM, Schneider A, Pannetier S, Heron D, Hanauer A (2010) Coffin-Lowry syndrome. Eur J Hum Genet 18:627-633.

Poirier R, Jacquot S, Vaillend C, Soutthiphong AA, Libbey M, Davis S, Laroche S, Hanauer A, Welzl H, Lipp HP, Wolfer DP (2007) Deletion of the Coffin-Lowry syndrome gene Rsk2 in mice is associated with impaired spatial learning and reduced control of exploratory behavior. Behav Genet 37:3150.

Powell SB, Zhou X, Geyer MA (2009) Prepulse inhibition and genetic mouse models of schizophrenia. Behav Brain Res 204:282-294.

Puig MV, Celada P, Diaz-Mataix L, Artigas F (2003) In vivo modulation of the activity of pyramidal neurons in the rat medial prefrontal cortex by 5-HT2A receptors: relationship to thalamocortical afferents. Cereb Cortex 13:870-882.

Romeo Y, Zhang X, Roux PP (2012) Regulation and function of the RSK family of protein kinases. Biochem J 441:553-569.

Roth BL, Xia Z (2004) Molecular and cellular mechanisms for the polarized sorting of serotonin receptors: relevance for genesis and treatment of psychosis. Crit Rev Neurobiol 16:229-236.

Schneider A, Maas SM, Hennekam RC, Hanauer A (2013) Identification of the first deep intronic mutation in the RPS6KA3 gene in a patient with a severe form of Coffin-Lowry syndrome. Eur J Med Genet 56:150-152.

Scruggs JL, Patel S, Bubser M, Deutch AY (2000) DOI-Induced activation of the cortex: dependence on 5HT2A heteroceptors on thalamocortical glutamatergic neurons. J Neurosci 20:8846-8852.

Sheffler DJ, Kroeze WK, Garcia BG, Deutch AY, Hufeisen SJ, Leahy P, Bruning JC, Roth BL (2006) p90 ribosomal $S 6$ kinase 2 exerts a tonic brake on $\mathrm{G}$ protein-coupled receptor signaling. Proc Natl Acad Sci U S A 103:4717-4722.

Sivagamasundari U, Fernando H, Jardine P, Rao JM, Lunt P, Jayewardene SL (1994) The association between Coffin-Lowry syndrome and psychosis: a family study. J Intellect Disabil Res 38 ( Pt 5):469-473.

Strachan RT, Allen JA, Sheffler DJ, Roth BL (2010a) p90 Ribosomal S6 kinase 2, a novel GPCR kinase, is required for growth factor-mediated attenuation of GPCR signaling. Biochemistry 49:2657-2671.

Strachan RT, Sciaky N, Cronan MR, Kroeze WK, Roth BL (2010b) Genetic deletion of p90 ribosomal S6 kinase 2 alters patterns of 5-hydroxytryptamine 2A serotonin receptor functional selectivity. Mol Pharmacol 77:327-338.

Strachan RT, Sheffler DJ, Willard B, Kinter M, Kiselar JG, Roth BL (2009) Ribosomal S6 kinase 2 directly phosphorylates the 5-hydroxytryptamine $2 \mathrm{~A}(5-\mathrm{HT} 2 \mathrm{~A})$ serotonin receptor, thereby modulating 
5-HT2A signaling. J Biol Chem 284:5557-5573.

Trivier E, De Cesare D, Jacquot S, Pannetier S, Zackai E, Young I, Mandel JL, Sassone-Corsi P, Hanauer A (1996) Mutations in the kinase Rsk-2 associated with Coffin-Lowry syndrome. Nature 384:567570.

Woolley DW, Shaw E (1954) A Biochemical and Pharmacological Suggestion About Certain Mental Disorders. Proc Natl Acad Sci U S A 40:228-231.

Xing J, Ginty DD, Greenberg ME (1996) Coupling of the RAS-MAPK pathway to gene activation by RSK2, a growth factor-regulated CREB kinase. Science 273:959-963.

Yadav PN, Kroeze WK, Farrell MS, Roth BL (2011) Antagonist functional selectivity: 5-HT2A serotonin receptor antagonists differentially regulate $5-\mathrm{HT} 2 \mathrm{~A}$ receptor protein level in vivo. J Pharmacol Exp Ther 339:99-105.

Yadav PN, Abbas AI, Farrell MS, Setola V, Sciaky N, Huang XP, Kroeze WK, Crawford LK, Piel DA, Keiser MJ, Irwin JJ, Shoichet BK, Deneris ES, Gingrich J, Beck SG, Roth BL (2010) The presynaptic component of the serotonergic system is required for clozapine's efficacy. Neuropsychopharmacology 36:638-651.

Yang X, Matsuda K, Bialek P, Jacquot S, Masuoka HC, Schinke T, Li L, Brancorsini S, Sassone-Corsi P, Townes TM, Hanauer A, Karsenty G (2004) ATF4 is a substrate of RSK2 and an essential regulator of osteoblast biology; implication for Coffin-Lowry Syndrome. Cell 117:387-398.

Zhu H, Pleil KE, Urban DJ, Moy SS, Kash TL, Roth BL (2014) Chemogenetic inactivation of ventral hippocampal glutamatergic neurons disrupts consolidation of contextual fear memory. Neuropsychopharmacology 39:1880-1892. 


\subsection{FIGURE LEGENDS:}

Figure 1. Disruption of the RSK2 gene attenuated the effectiveness of $5-\mathrm{HT}_{2} \mathrm{~A}$ receptor antagonist on normalizing the PCP or AMPH-induced psychosis. A. Disruption of RSK2 gene significantly increased PCP-induced hyperlocomotion (interaction of genotype and time, $\mathrm{F}(17,459)=2.35, \mathrm{p}=0.0018$; effect of genotype, $\mathrm{F}(1,459)=4.737, \mathrm{p}=0.0384$, two-way ANOVA). Animals were injected with vehicle and placed into open field chambers, 30 min later mice were injected with $6 \mathrm{mg} / \mathrm{kg}$ PCP and the total distance traveled was determined. B. Disruption of RSK2 gene significantly decreased the effectiveness of MDL on normalizing the PCP-induced locomotion (interaction of genotype and time, $\mathrm{F}(17,476)=2.913, \mathrm{p}<0.0001$; effect of genotype, $\mathrm{F}(1,476)=3.582, \mathrm{p}=0.0688$, two-way ANOVA). Animals were pretreated with $0.5 \mathrm{mg} / \mathrm{kg} \mathrm{MDL}$ and placed into open field chambers, 30 min later mice were injected with $6 \mathrm{mg} / \mathrm{kg}$ PCP and the total distance traveled was determined. C. Disruption of RSK2 gene significantly increased AMPH-induced hyperlocomotion (interaction of genotype and time, $F(17,238)=3.899, \mathrm{p}<0.0001$; effect of genotype, $\mathrm{F}(1,238)=7.257$, $\mathrm{p}=0.0175$, two-way ANOVA). Animals were injected with vehicle and placed into open field chambers, 30 min later mice were injected with $6 \mathrm{mg} / \mathrm{kg}$ AMPH and the total distance traveled was determined. D. Disruption of RSK2 gene significantly decreased the effectiveness of MDL on normalizing the AMPH-induced locomotion (interaction of genotype and time, $\mathrm{F}(17,238)=3.43, \mathrm{p}<0.0001$; effect of genotype, $\mathrm{F}(1,238)=7.155, \mathrm{p}=0.0181$, two-way ANOVA) . Animals were pretreated with $0.5 \mathrm{mg} / \mathrm{kg} \mathrm{MDL}$ and placed into open field chambers, 30 min later mice were injected with $6 \mathrm{mg} / \mathrm{kg}$ AMPH and the total distance traveled was determined. E. Disruption of RSK2 gene decreased the effectiveness of MDL on normalizing the PCP-induced disruption of sensorimotor gating. Animal received vehicle, $6 \mathrm{mg} / \mathrm{kg} \mathrm{PCP}, 0.5 \mathrm{mg} / \mathrm{kg} \mathrm{MDL}+6 \mathrm{mg} / \mathrm{kg}$ PCP. MDL significantly 
normalized the PCP-induced disruption of PPI in WT mice $(F(1,40)=12.49, \mathrm{p}=0.0021$, two-way ANOVA), but not in RSK2 KO mice $(\mathrm{F}(1,42)=0.5965, \mathrm{p}=0.4485$, two-way ANOVA, $\mathrm{n}=11)$. Two-way ANOVA followed by Bonferroni post test for multiple comparisons, $* \mathrm{p}<0.05$, ** $\mathrm{p}<0.01, * * * \mathrm{p}<0.001$

Figure 2. Forebrain-specific disruption of RSK2 gene in EMX-RSK2 KO mice. A. Schematic representation of the wild-type RSK2 allele, targeting construct, targeted allele, conditional allele, and null allele. Exon 4 is shown as a red box, and exons 3, 5, 6 are shown as black boxes. LoxP sequences are shown as black triangles, FRT sequences are shown as orange triangles, and F3 sequences are shown as blue triangles. Grey boxes indicate the neomycin (NeoR) and puromycin (PuroR) resistance sequences used for double positive selection. Striped boxes represent the frame shift of exons 5 and 6 after removing exon 4 . The conditional $\mathrm{KO}$ allele was generated by partial excision of the targeted allele using Flp-Deleter mice, and the null allele was generated by excision of exon 4 from conditional allele using EMX-Cre mice. B. Genotyping of EMX-RSK2 KO mice. Male homozygous EMX-Cre mice were crossed with female heterozygous conditional RSK2 mice. Male litters showed either a 353bp wild type allele (lane 1) or 525bp conditional allele (lane 2). Female litters showed either wild type alleles (lane 3) or heterozygous alleles (wild type and conditional allele, lane 4). All litters showed a 102bp amplicon of EMX-Cre transgene in the low panel. C. Western blot analysis of RSK2 ( 90 kDa) in protein lysates prepared from the cerebral cortex of conditional RSK2 mice (lane1), EMX-Cre mice (lane2) and EMX-RSK2 KO mice (lane3) at postnatal day 56. Comparable staining of $\beta$ actin was used to verify equivalent protein loading. D, E. Immunofluorescence staining analysis of RSK2 protein (green) in the cortex (CTX), hippocampus (HFC) and thalamus (Thal) from EMX-RSK2 KO mice (D) or littermate control mice (E). Neurons were counterstained with 
NeuroTace 530/615 (red). Scale bar is 20 um.

Figure 3. EMX-RSK2 KO mice exhibited normal growth and basal behaviors in their naïve state. EMX-RSK2 KO mice $(n=7)$ showed a normal growth compared with control mice $(n=6)$ $(\mathbf{A}, \mathrm{F}(1,66)=1.253, \mathrm{p}=0.2868$, two-way ANOVA). In novelty induced locomotion test, there is a compatible locomotor response between two genotypes $(\mathbf{B}, \mathrm{F}(1,121)=0.3097, \mathrm{p}=0.589$, two-way ANOVA). EMX-RSK2 KO mice showed a normal anxiety level in the elevated plus maze test (C, $\mathrm{F}(1,36)=0.4865, \mathrm{p}=0.4944$, two-way ANOVA ) and a normal motor coordination in the accelerating rotarod test $(\mathbf{D}, \mathrm{F}(1,44)=1.178, \mathrm{p}=0.3009$, two-way ANOVA $)$. In the sociability and social novelty test, EMX-RSK2 KO mice showed a comparable preference compared with the littermate control mice $(\mathbf{E}, \quad$ sociability, $\mathrm{F}(1,10),=2.167, \mathrm{p}=0.1718 ;$ social novelty, $\mathrm{F}(1,11)=0.1802, \mathrm{p}=0.6794$, two-way ANOVA ). EMX-RSK2 KO mice also showed a normal contextual and cued freezing behaviors in fear conditioning test (F, contextual freezing, $\mathrm{t}(11)=0.2441, \mathrm{p}=0.8116$; cued freezing, $\mathrm{t}(1,11)=0.8154, \mathrm{p}=04322$, unpaired $\mathrm{t}$-test $)$. In the Morris water maze test, EMX-RSK2 KO mice showed a comparable preference to the target quadrant during the memory test $(\mathbf{G}, \mathrm{F}(1,33)=0.1732, \mathrm{p}=0.6853) .{ }^{*} \mathrm{p}<0.05, * * \mathrm{p}<0.01, * * * \mathrm{p}<0.001$.

Figure 4. Forebrain-specific disruption of RSK2 gene attenuated the effectiveness of 5-HT $2 \mathrm{~A}$ receptor antagonist on normalizing the PCP- or AMPH-induced psychosis. A. There was no significant difference between EMX-RSK2 $\mathrm{KO}$ mice and control mice in PCP-induced hyperlocomotion (interaction of genotype and time, $F(17,340)=0.9219, p=0.5482$; effect of 
genotype, $\mathrm{F}(1,340)=0.4912$, $\mathrm{p}=0.04915$, two-way ANOVA). Animals were injected with vehicle and placed into open field chambers, 30 min later mice were injected with $6 \mathrm{mg} / \mathrm{kg}$ PCP and the total distance traveled was determined. B. Forebrain-specific disruption of RSK2 gene significantly decrease the effectiveness of MDL on normalizing the PCP-induced locomotion (interaction of genotype and time, $\mathrm{F}(17,340)=4.283, \mathrm{p}<0.0001$; effect of genotype, $\mathrm{F}(1,340)=5.379, \mathrm{p}=0.0311$, two-way ANOVA). Animals were pretreated with $0.2 \mathrm{mg} / \mathrm{kg} \mathrm{MDL}$ and placed into open field chambers, 30 min later mice were injected with $6 \mathrm{mg} / \mathrm{kg} \mathrm{PCP}$ and the total distance traveled was determined. C. Forebrain-specific disruption of RSK2 gene significantly increased AMPH-induced hyperlocomotion (interaction of genotype and time, $\mathrm{F}(17,187)=5.725, \mathrm{p}<0.0001$; effect of genotype, $\mathrm{F}(1,187)=11.63, \mathrm{p}=0.0058$, two-way ANOVA). Animals were injected with vehicle and placed into open field chambers, 30 min later mice were injected with $3 \mathrm{mg} / \mathrm{kg}$ AMPH and the total distance traveled was determined. D.MDL was less effectiveness to normalize AMPH-induced hyperlocomotion (interaction of genotype and time, $\mathrm{F}(17,170)=4.591, \mathrm{p}<0.0001$; effect of genotype, $\mathrm{F}(1,170)=10.09, \mathrm{p}=0.0099$, two-way ANOVA) . Animals were injected with MDL $(0.2 \mathrm{mg} / \mathrm{kg})$ and placed into open field chambers, 30 min later mice were injected with $3 \mathrm{mg} / \mathrm{kg}$ AMPH and the total distance traveled was determined. E. PCP disrupted the sensorimotor gating in both genotypes in a comparable manner. Animal received vehicle, $4 \mathrm{mg} / \mathrm{kg}$ or $6 \mathrm{mg} / \mathrm{kg} \mathrm{PCP}$, and then followed by measuring the acoustic startle response. PCP significantly disrupted prespulse inhibition in control mice $(F(2,64)=7.503, p=0.0021$, twoway ANOVA; $\mathrm{n}=12)$ and EMX-RSK2 KO mice $(\mathrm{F}(2,82)=10.48, \mathrm{p}=0.0002$, two-way ANOVA; $\mathrm{n}=15)$. F. Forebrain-specific disruption of RSK2 gene significantly decreased the effectiveness of MDL on normalizing the PCP-induced disruption of sensorimotor gating. Animal received vehicle, $6 \mathrm{mg} / \mathrm{kg}$ PCP, $0.2 \mathrm{mg} / \mathrm{kg} \mathrm{MDL}+6 \mathrm{mg} / \mathrm{kg} \mathrm{PCP}$ or $0.5 \mathrm{mg} / \mathrm{kg} \mathrm{MDL}+6 \mathrm{mg} / \mathrm{kg} \mathrm{PCP}$. MDL 
normalized the disruption of PPI by PCP in control mice $(\mathrm{F}(2,66)=4.818, \mathrm{p}=0.0146$, two-way ANOVA; $n=12)$, but it has no effect in EMX-RSK2 KO mice $(F(2,84)=0.297, p=0.7446$, twoway ANOVA; $\mathrm{n}=15) . * \mathrm{p}<0.05, * * \mathrm{p}<0.01, * * * \mathrm{p}<0.001$

Figure 5. 5- $\mathrm{HT}_{2 \mathrm{~A}}$ receptor signaling is augmented in EMX-RSK2 KO mice. A. Schematic diagram of brain regions analyzed in DOI-induced c-fos activation experiment. Green boxes represent the region of somatosensory cortex analyzed in this study. Numbers indicate the distance from bregma in millimeters. B, C. DOI-induced c-fos activation is increased in EMXRSK2 KO mice. Animals were injected with vehicle or $0.5 \mathrm{mg} / \mathrm{kg}$ DOI, $2 \mathrm{~h}$ later mice were perfused with $4 \%$ PFA, 40um frozen sections were cut and c-fos positive cells were determined by immunofluorescence (IF) staining. B. Representative figures of IF staining of DOI induced cfos activation (green). Nuclei were counterstained with DAPI (blue). Sale bar, 100um. C. DOIinduced c-fos gene activation in somatosensory cortex is significantly increased in EMX-RSK2 KO mice compared to littermate control mice $(\mathrm{F}(1,24)=5.993, \mathrm{p}=0.022$, two-way ANOVA; $\mathrm{n}=7)$. D. DOI-induced c-fos expression is increased in EMX-RSK2 KO mice. Animals were injected with $0.5 \mathrm{mg} / \mathrm{kg}$ DOI, $1 \mathrm{~h}$ later frontal cortexes were dissected, mRNAs were extracted and transcript levels of c-fos were determined by real-time PCR. DOI-induced c-fos gene expression in frontal cortex was significantly increased in EMX-RSK2 KO mice $(F(1,32)=4.93, p=0.0277$ two-way ANOVA; n=9). E. HTR to the 5- $\mathrm{HT}_{2 \mathrm{~A}}$ receptor partial agonist DOI was increased in EMX-RSK2 KO mice. Animals were injected with $0,0.5,1 \mathrm{mg} / \mathrm{kg}$ DOI and head twitches were scored over a 20 min period. DOI-induced head twitches were significantly increased in EMXRSK2 KO mice compared with littermate control mice $(F(2,36)=3.613, p=0.0372$, two-way ANOVA; n=10). F. HTR to the 5- $\mathrm{HT}_{2 \mathrm{~A}}$ receptor full agonist 5-HTP was increased in EMX- 
RSK2 KO mice. Animals were injected with 0, 50, 100, 200mg/kg 5-HTP and head twitches were scored over a 20 min period. DOI-induced head twitches were significantly increased in EMX-RSK2 KO mice compared with littermate control mice $(\mathrm{F}(3,24)=4.582, \mathrm{p}=0.0113$, twoway ANOVA; $\mathrm{n}=5) .{ }^{*} \mathrm{p}<0.05, * * \mathrm{p}<0.01, * * * \mathrm{p}<0.001$

Figure 6. 5-HT $2 \mathrm{~A}$ receptor expression was not altered in EMX-RSK2 KO mice. A. Representative sections of 5- $\mathrm{HT}_{2 \mathrm{~A}}$ receptor binding sites in the cerebral cortex of EMX-RSK2 KO mice and littermate control mice. Animal brains were cryosectioned and processed for ${ }^{125} \mathrm{I}-$ DOI (200 pM) in vitro binding with/ without the presence of $1 \mathrm{uM}$ ritanserin. A clear signal in the layer $\mathrm{V}$ of the cerebral cortex was observed and the mean pixel intensity/area determined (upper panel). The specificity of ${ }^{125}$ I-DOI binding was shown that no signal was detected in the presence of ritanserin (lower panel). B. Representative sections of 5- $\mathrm{HT}_{2 \mathrm{~A}}$ receptor immunoreactivity in cerebral cortex of EMX-RSK2 KO mice and littermate control mice. Animal brains were cryosectioned and stained with anti-5- $\mathrm{HT}_{2 \mathrm{~A}}$ receptor antibody and Alexa 488 conjugated antirabbit secondary antibody. A clear layer V band (green) was detected in the cerebral cortex. Arrow, signals of 5- $\mathrm{HT}_{2 \mathrm{~A}}$ receptor immunoreactivity in layer V. C. No difference in cortical ${ }^{125} \mathrm{I}-$ DOI autoradiography tracing intensities was observed between genotypes in anatomically matched frontal cortex sections or examined $(\mathrm{t}(8)=0.2448, \mathrm{p}=0.8128$, unpaired $\mathrm{t}$-test; $\mathrm{n}=5)$. D. No difference in cortical $5-\mathrm{HT}_{2 \mathrm{~A}}$ receptor abundance in layer $\mathrm{V}$ and peripheral layers was observed between genotypes in anatomically matched frontal cortex sections examined $(\mathrm{F}(1,8)=1.147, \mathrm{p}=0.3153$, two-way ANOVA; $\mathrm{n}=5)$. 
7.0 Acknowledgements: This work was supported by RO1MH61887 and U19MH82441 to BLR 


\section{Figure 1}

A
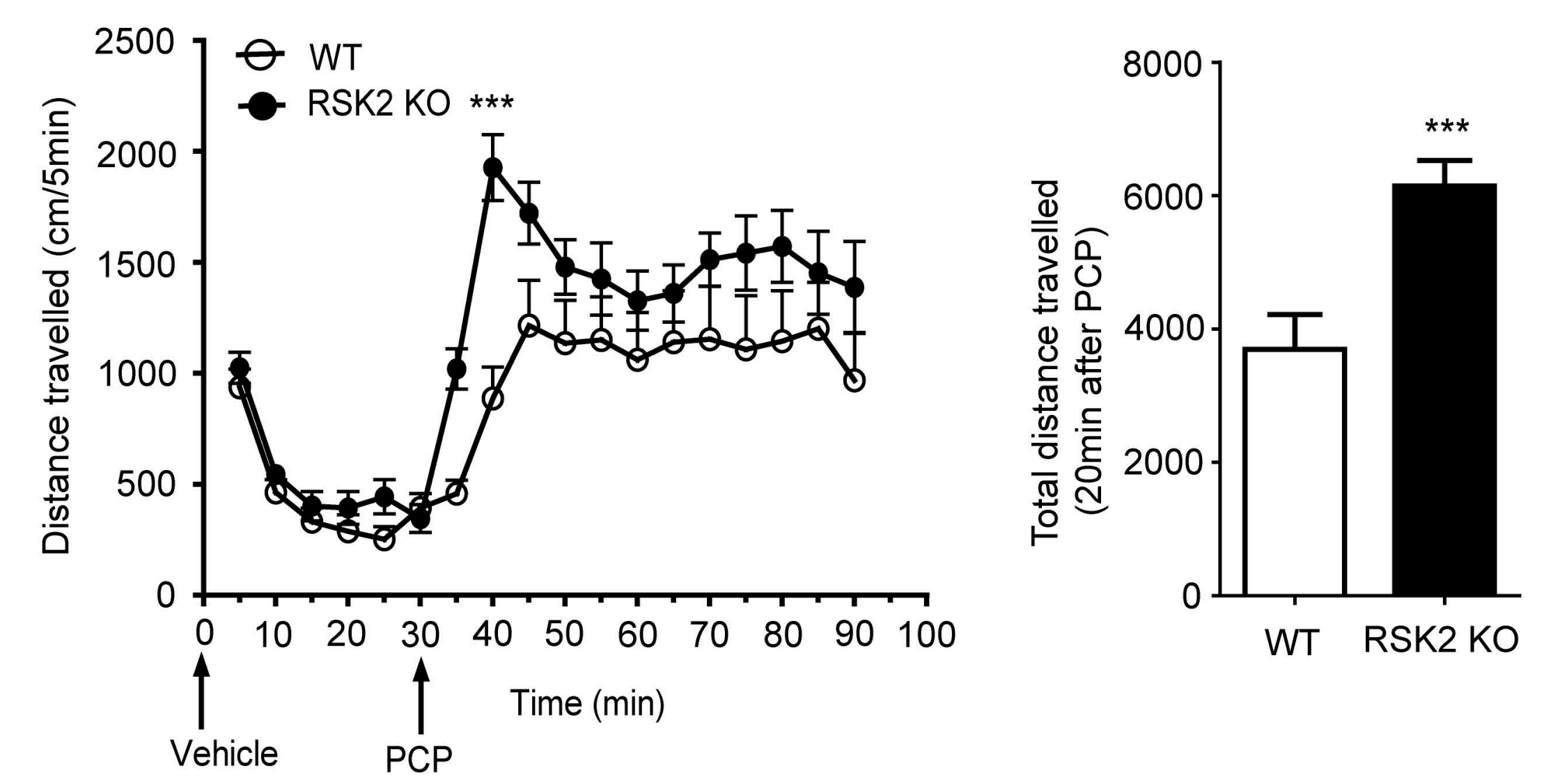

B
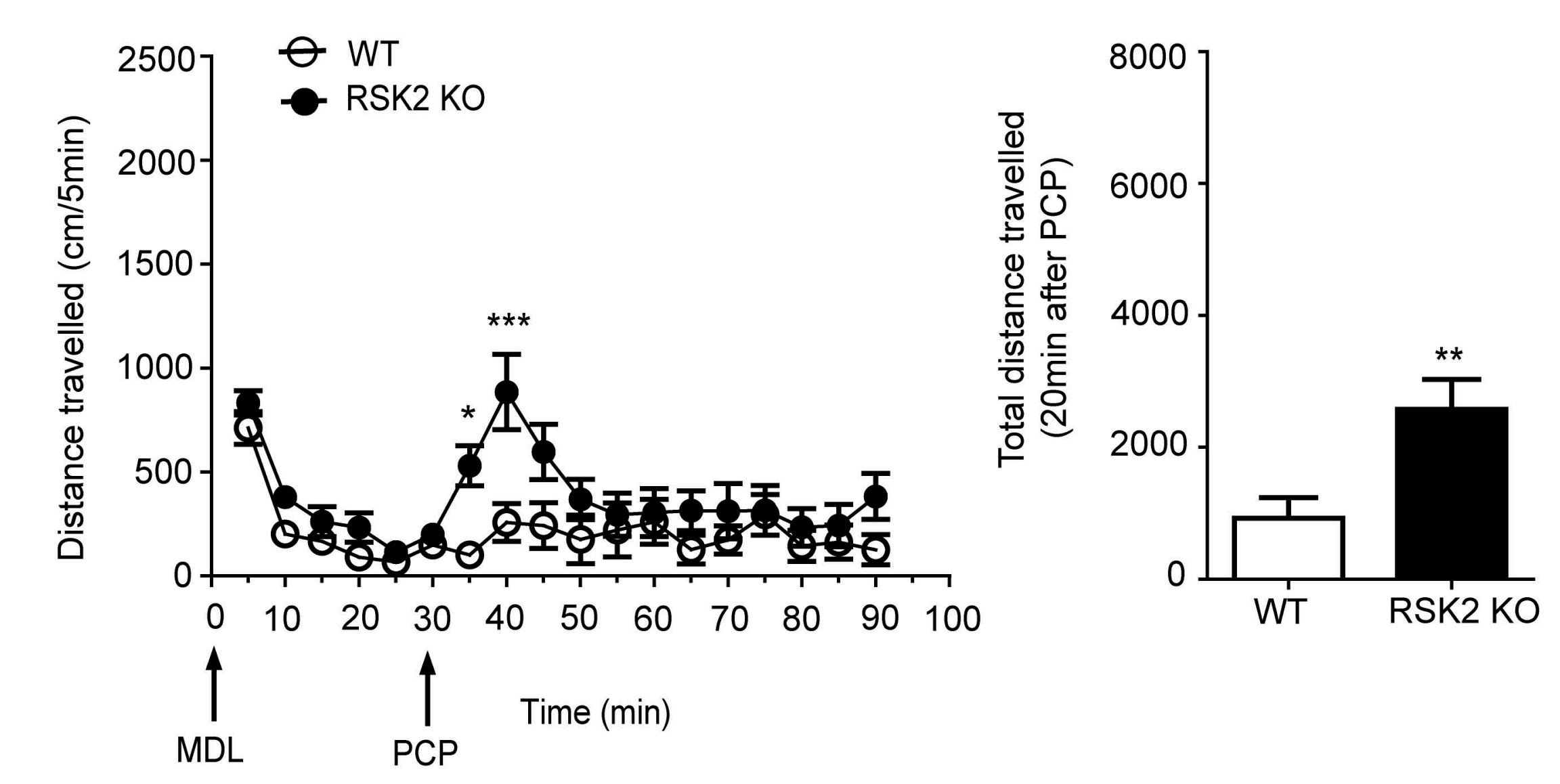

D

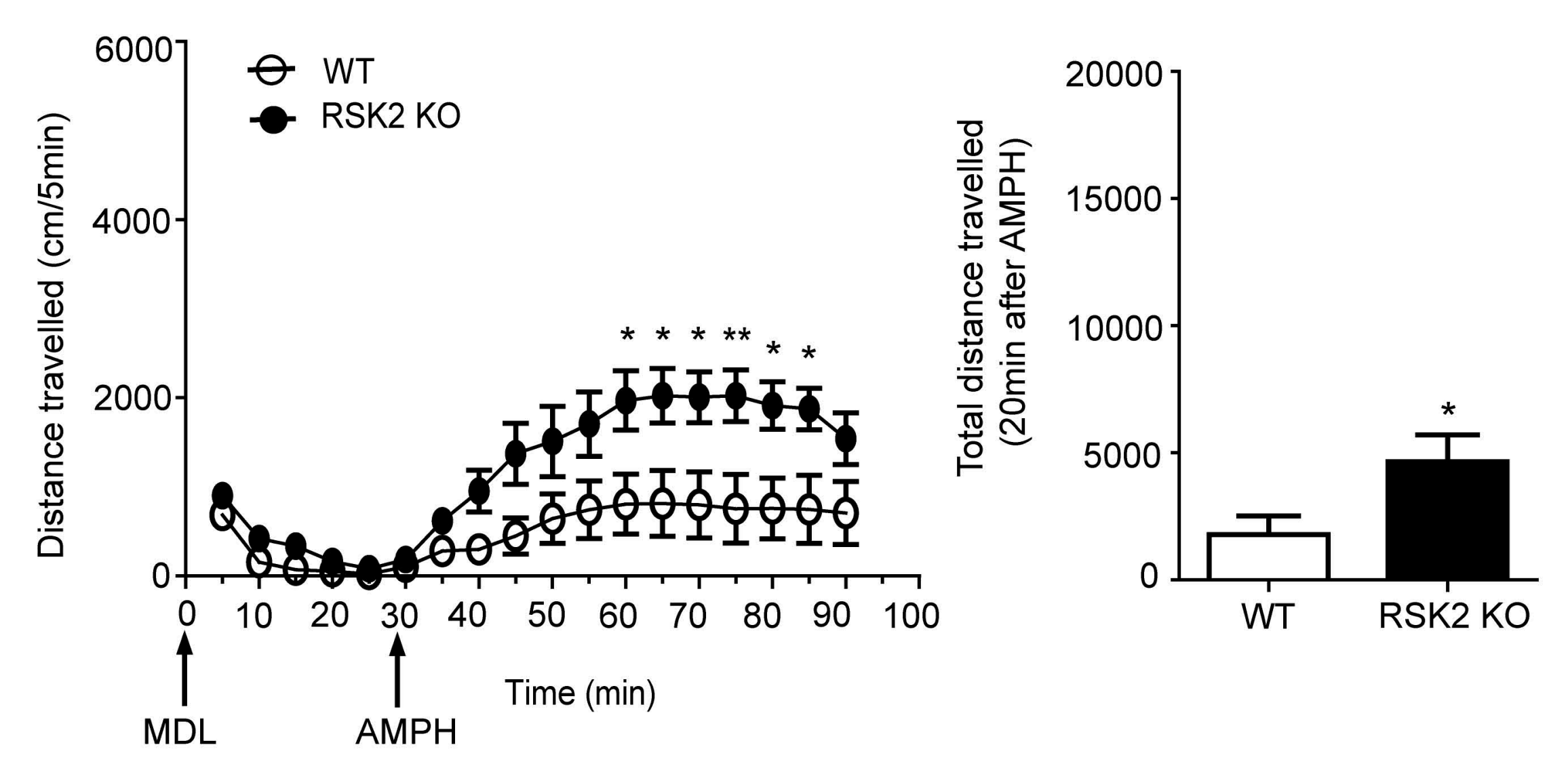

E

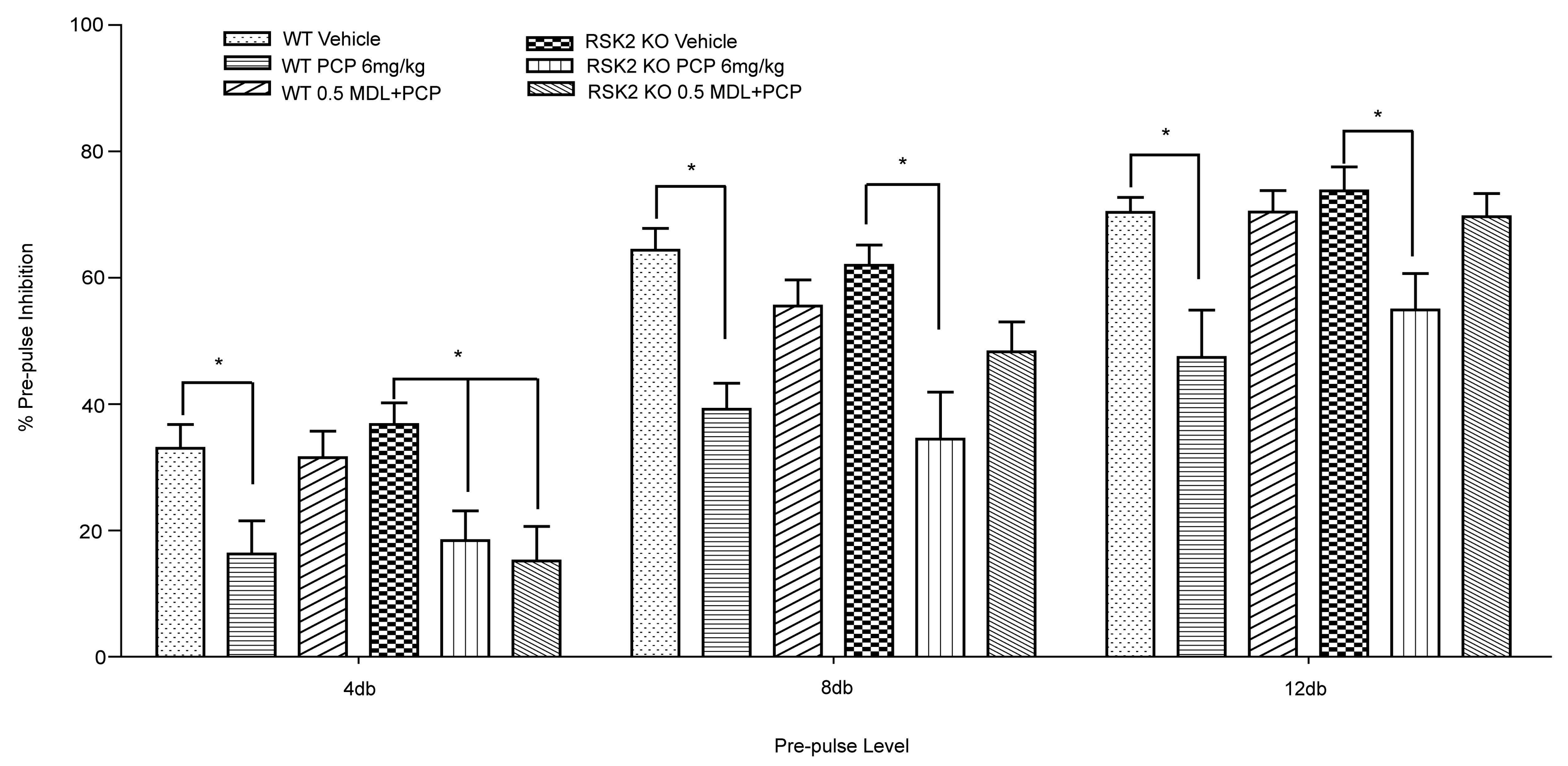




\section{Figure 2}

A

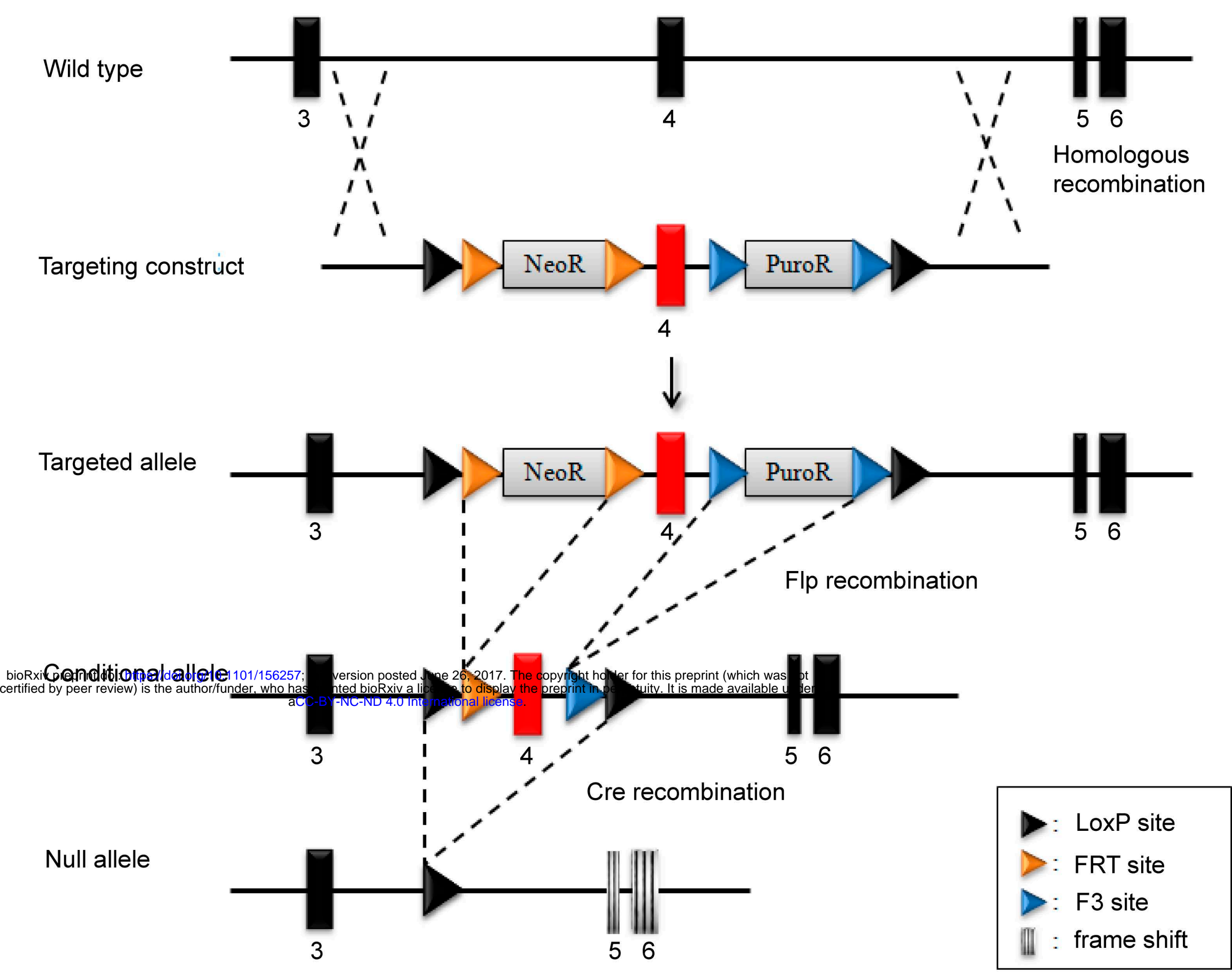

B

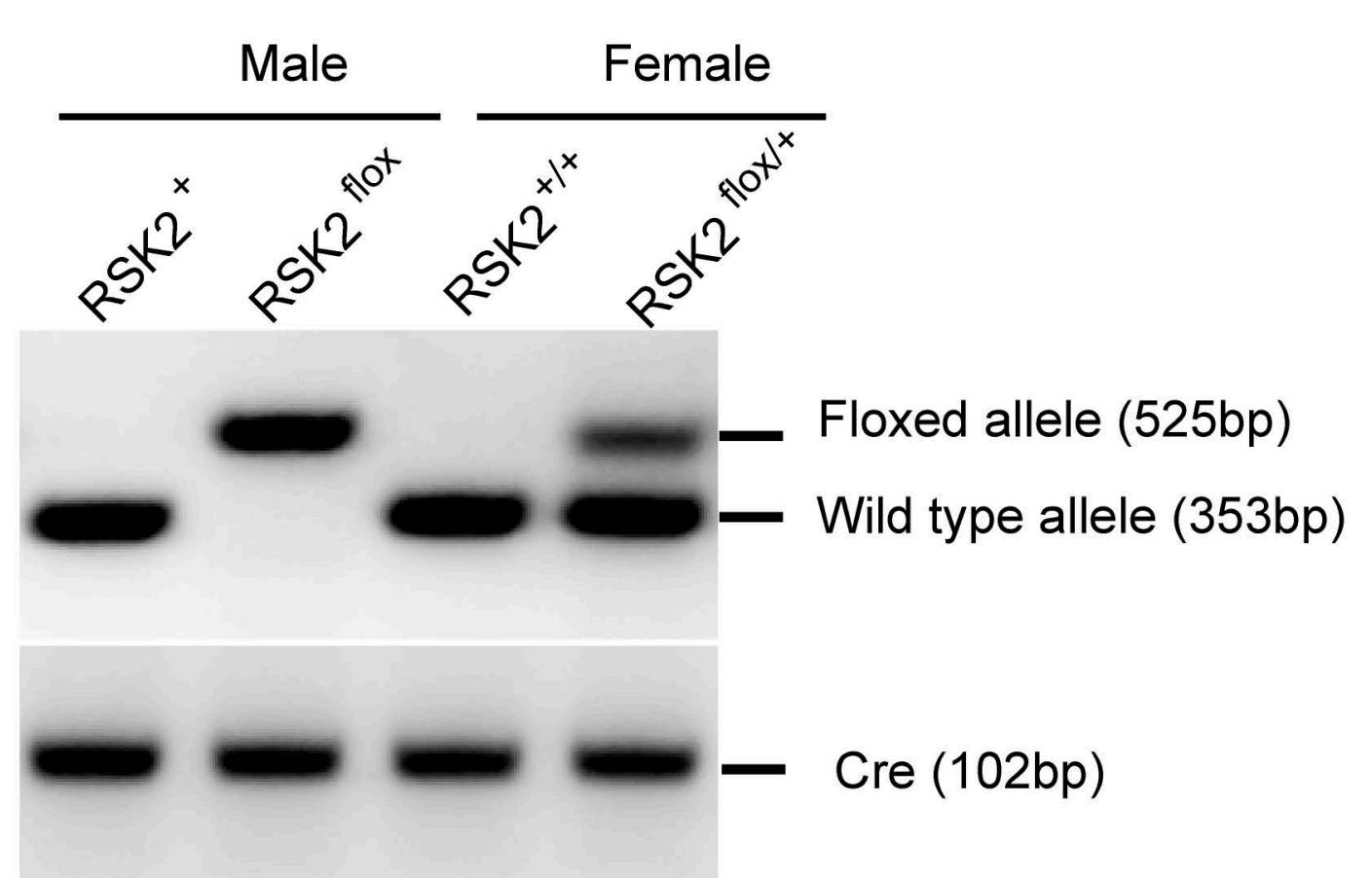

C

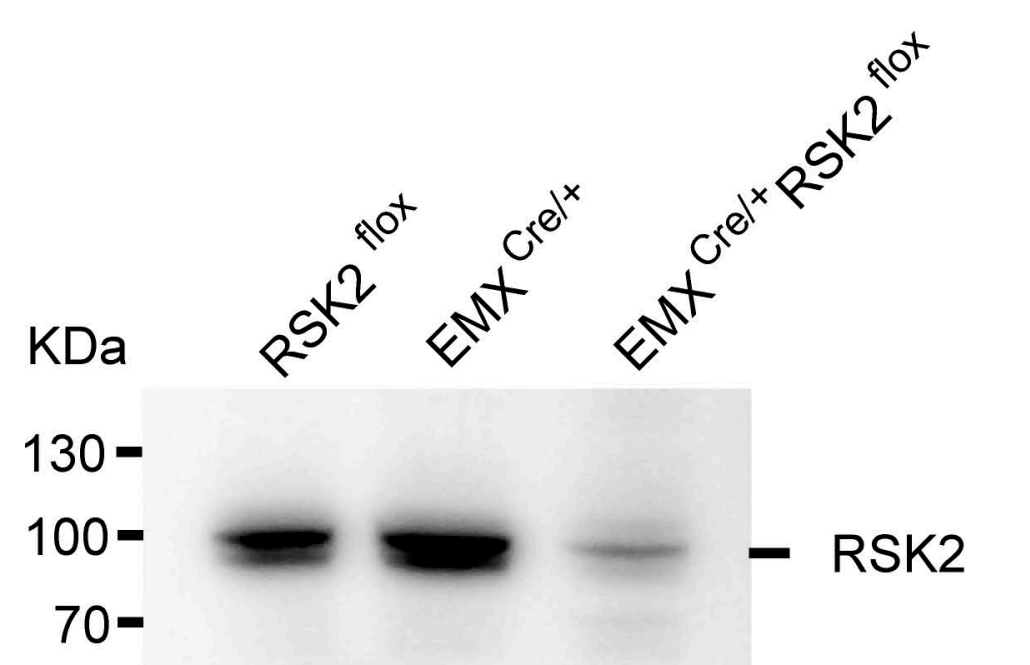

E
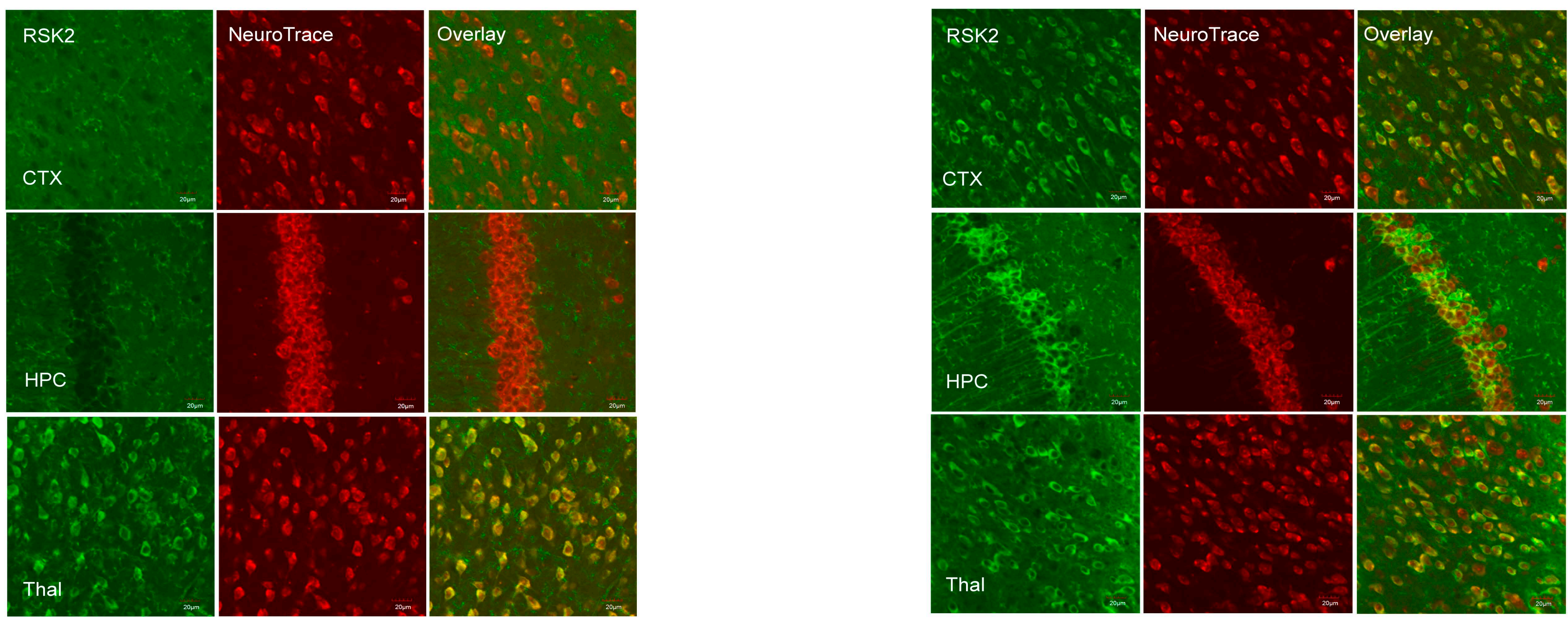
Figure 3

A

B

C
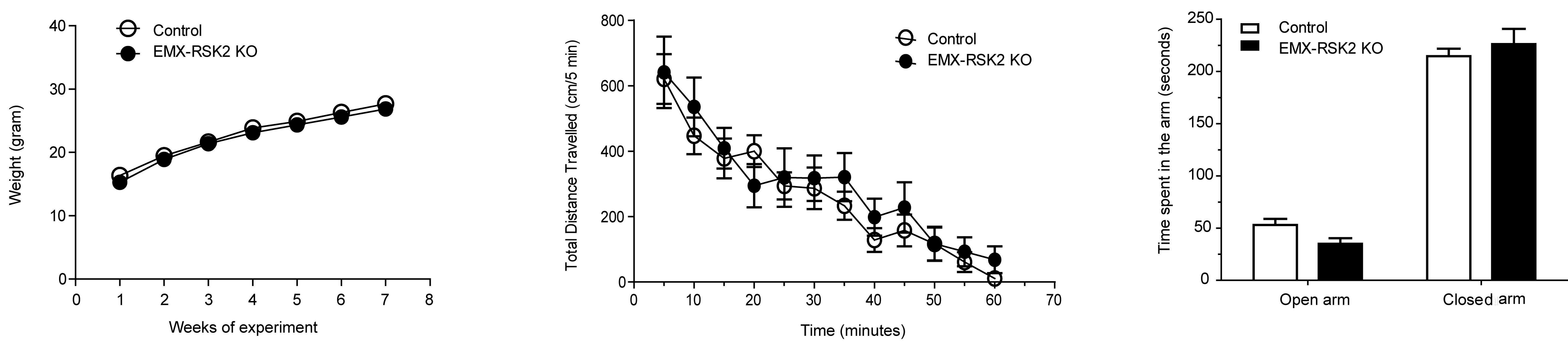

D

E
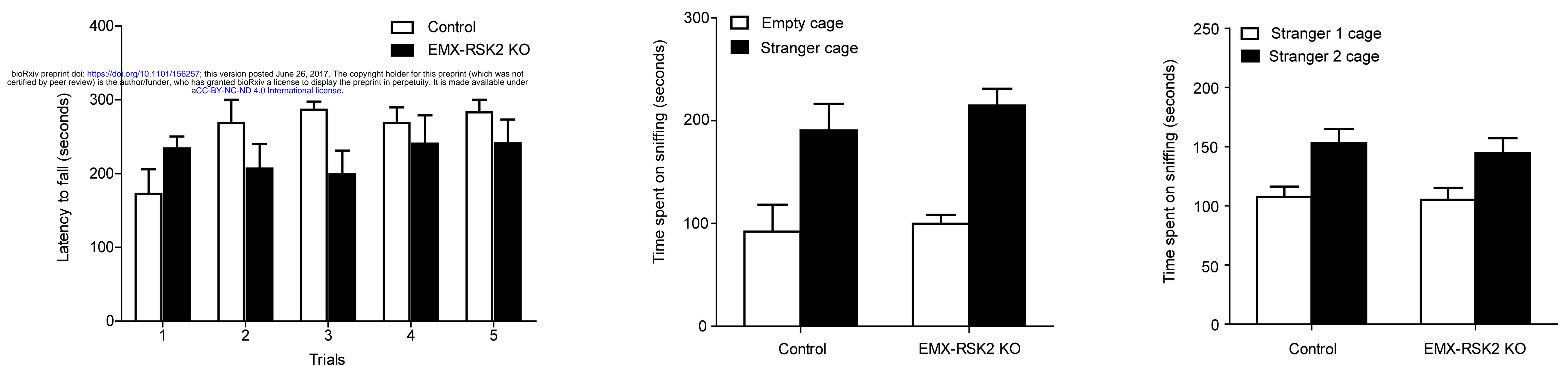

G
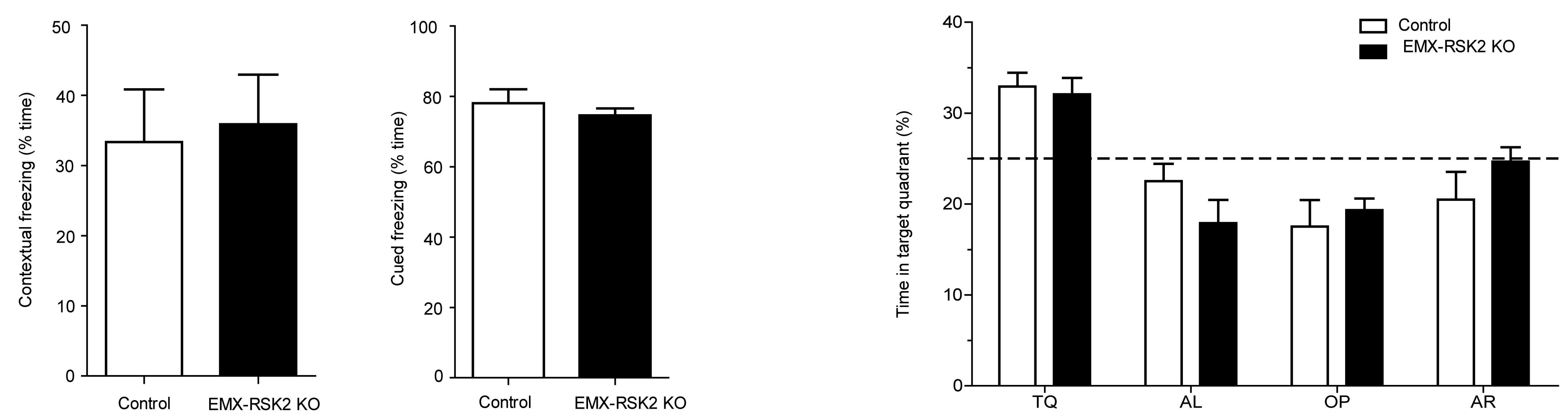


\section{Figure 4}
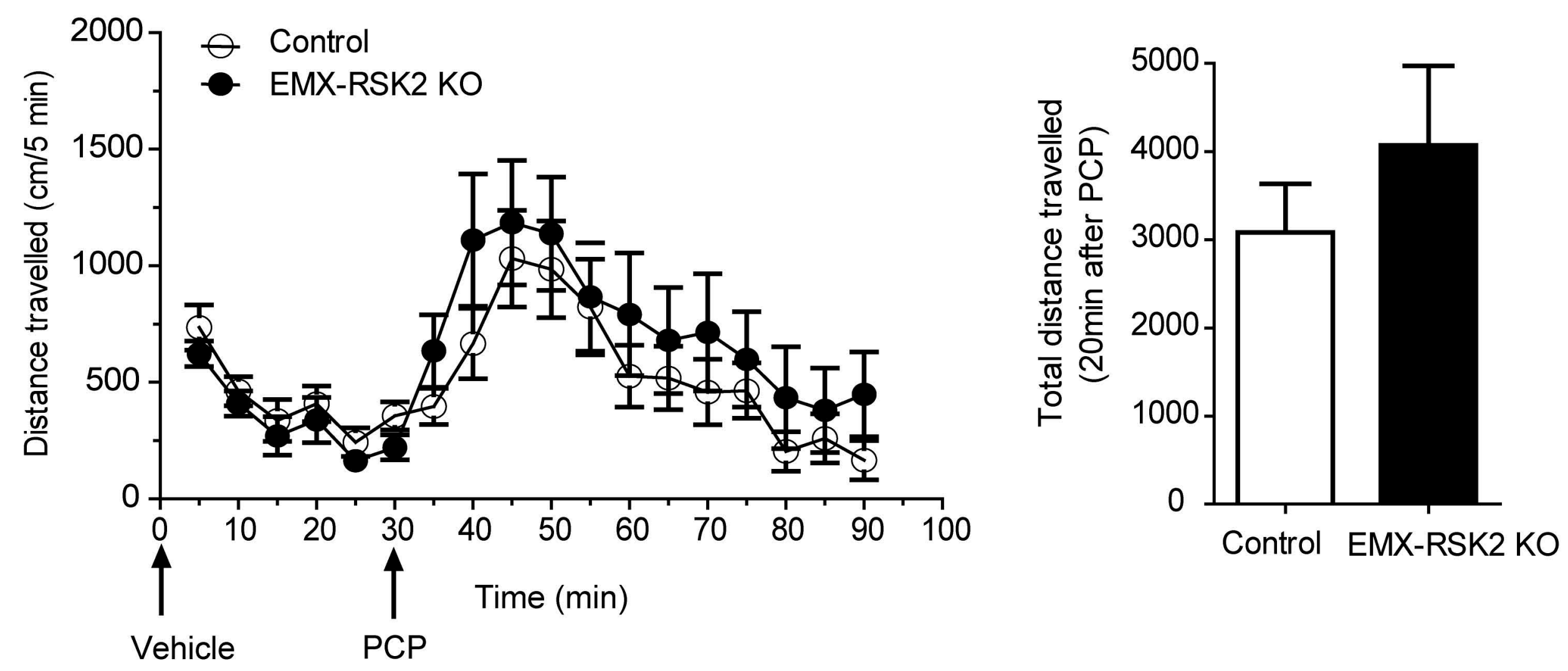

C

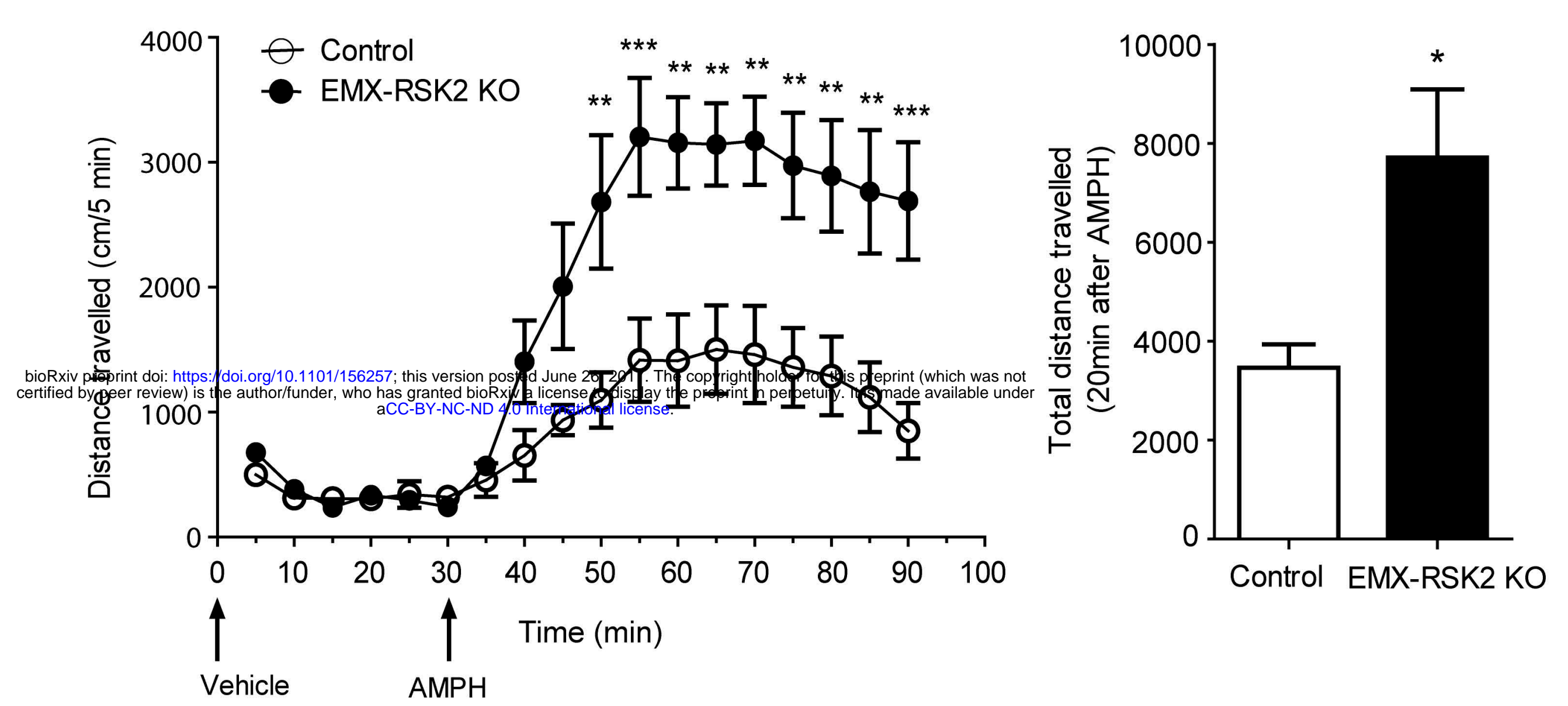

E

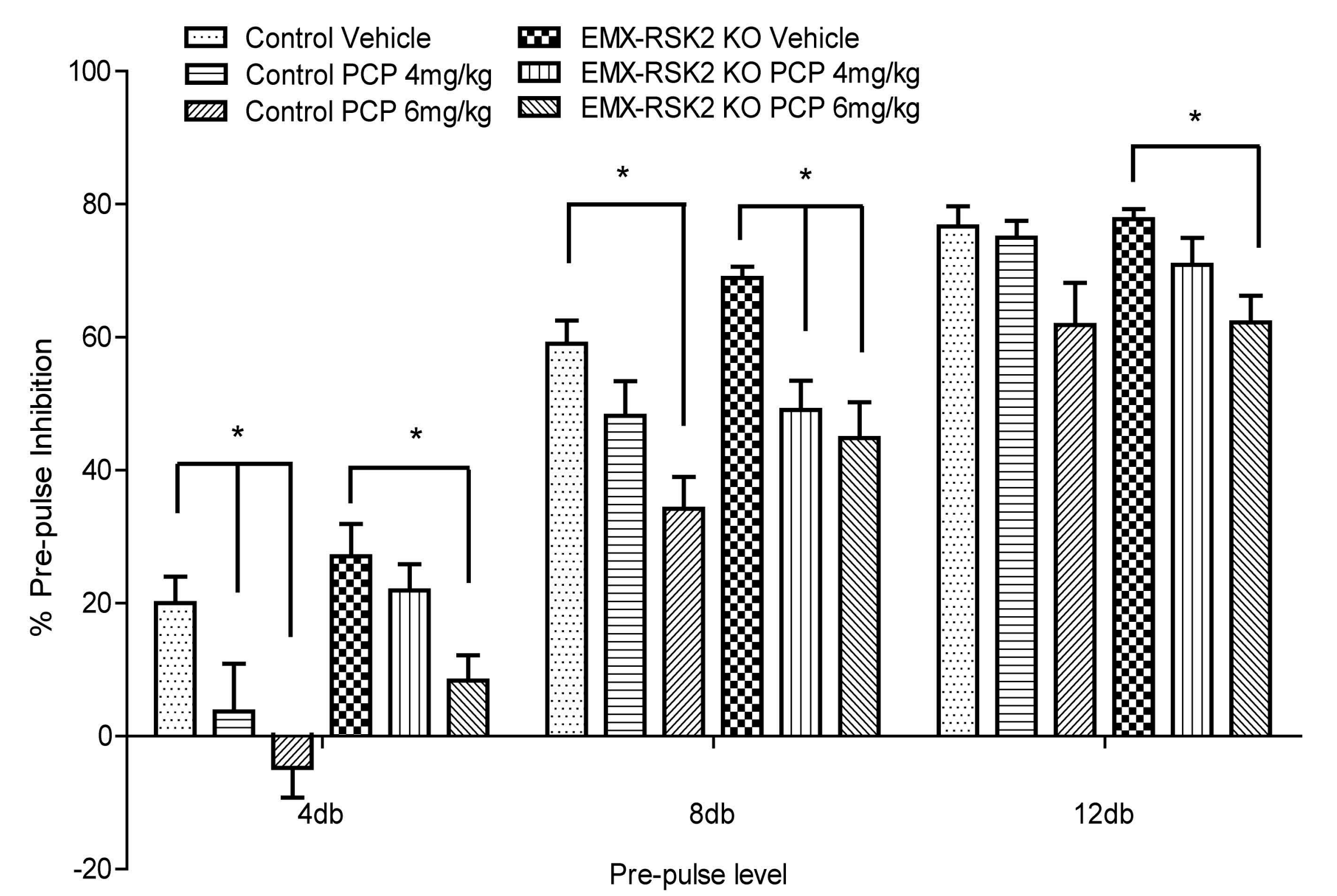

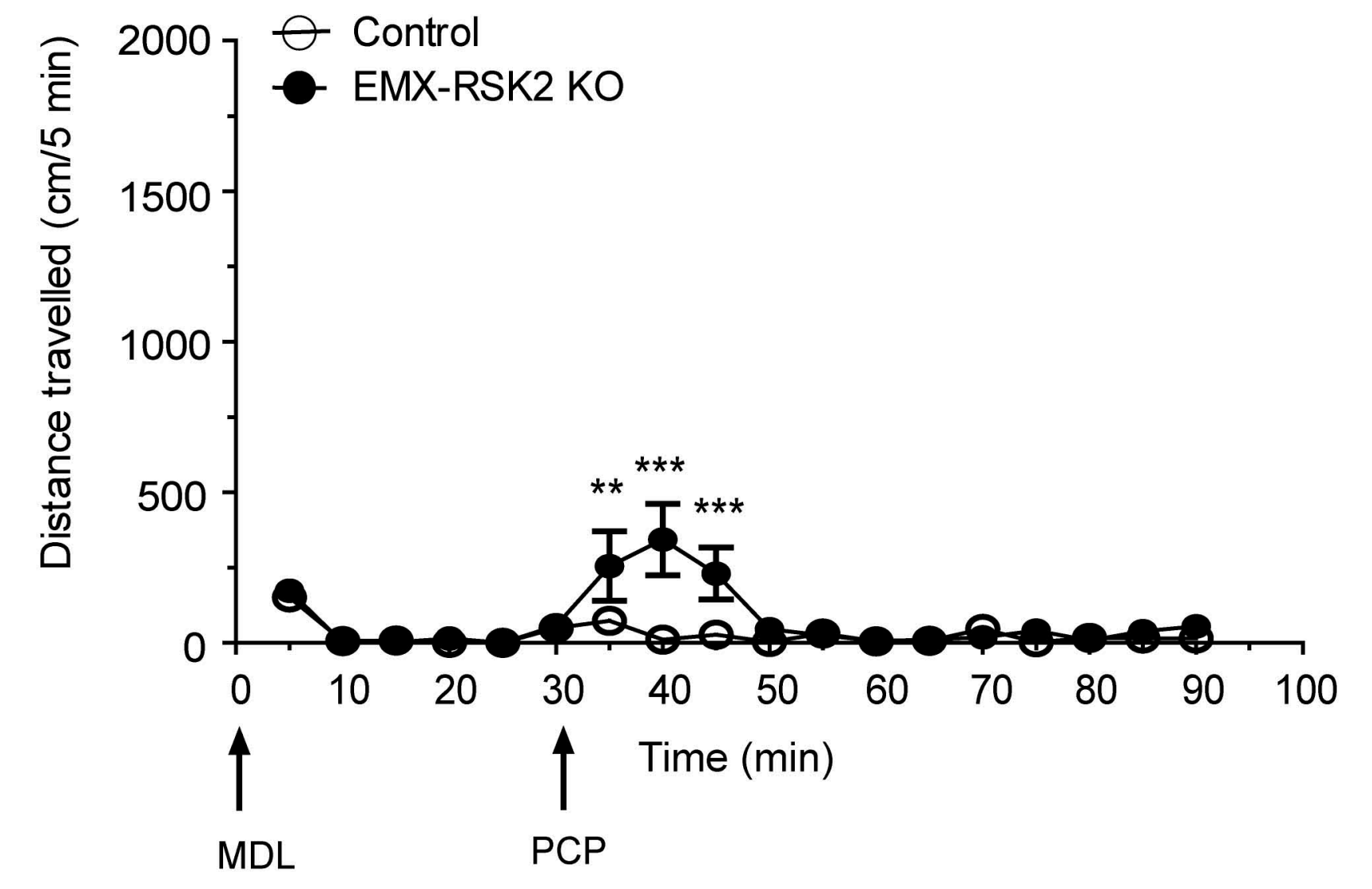

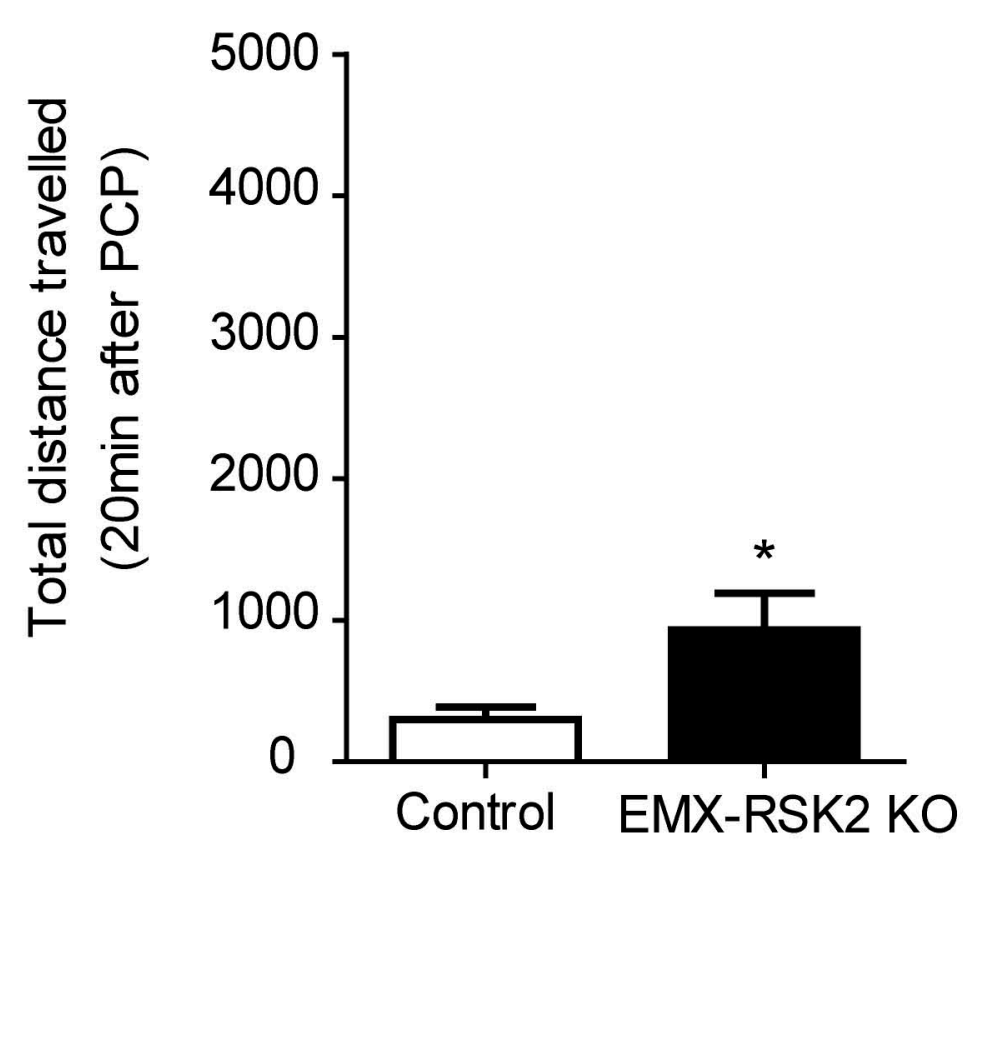

D
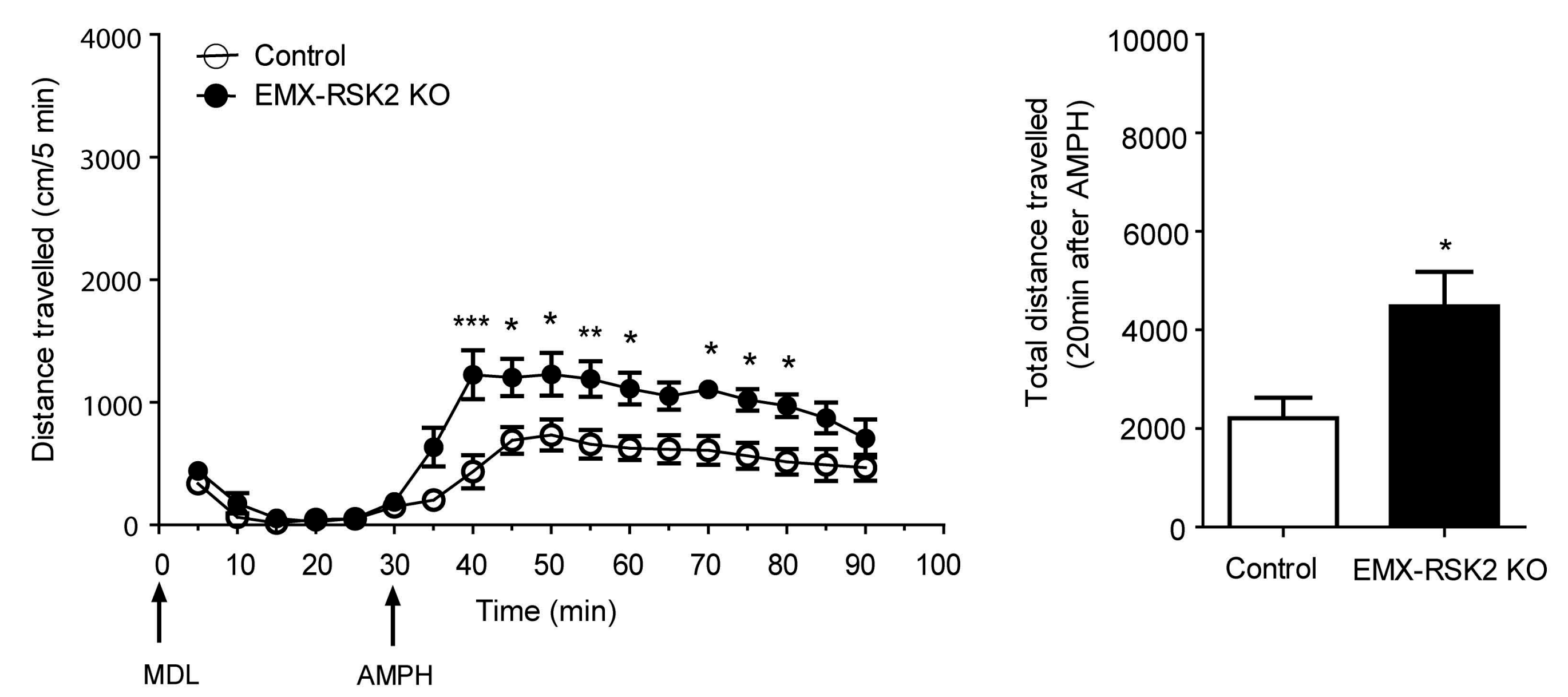

F

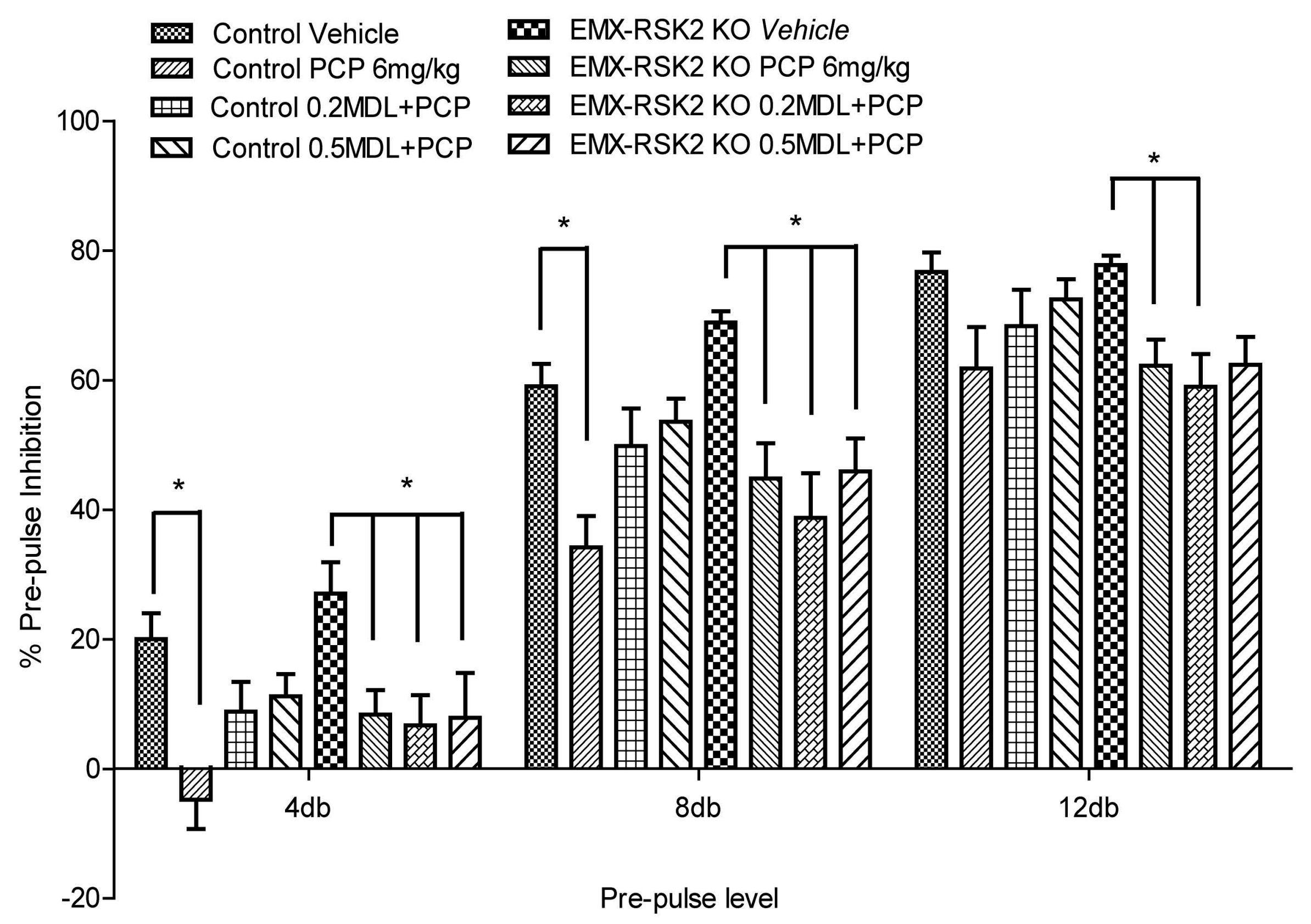


Figure 5

A

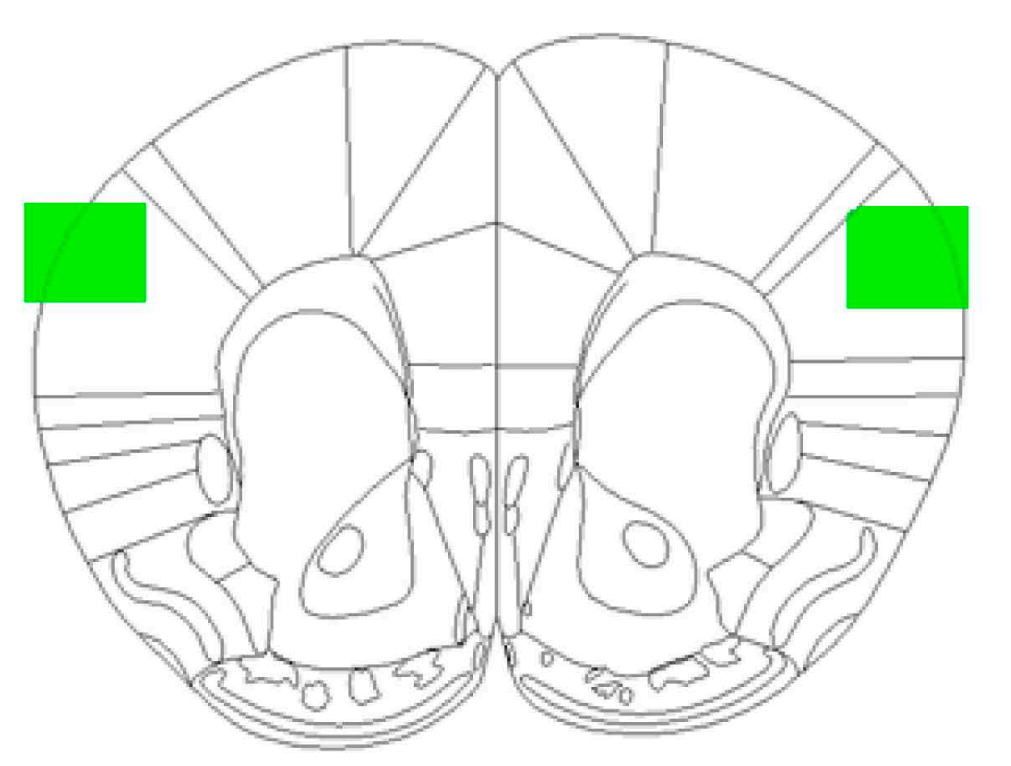

Somatosensory cortex

(Bregma 1.53mm)

B

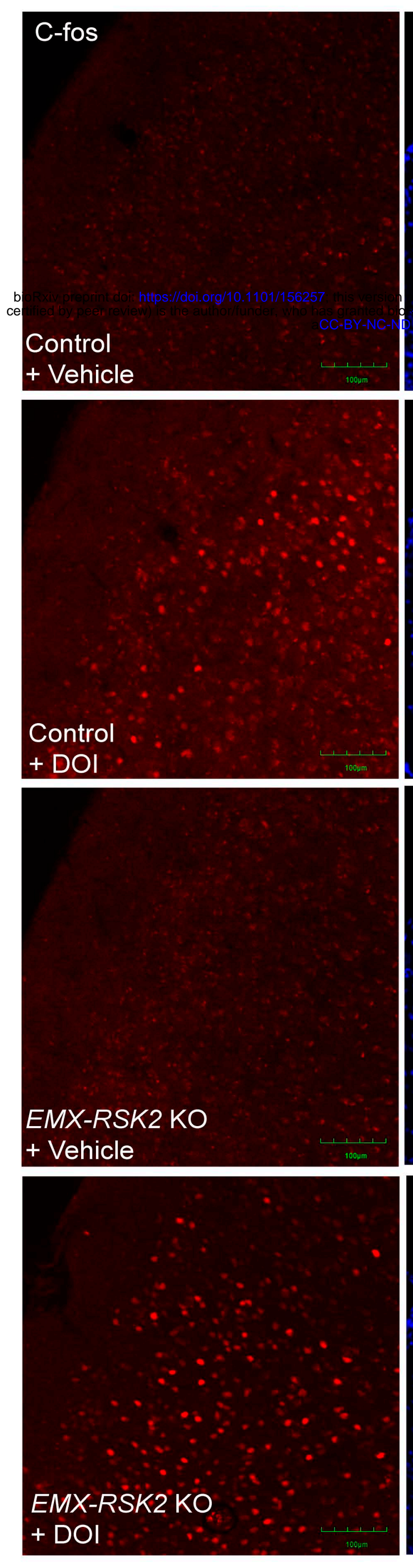

C

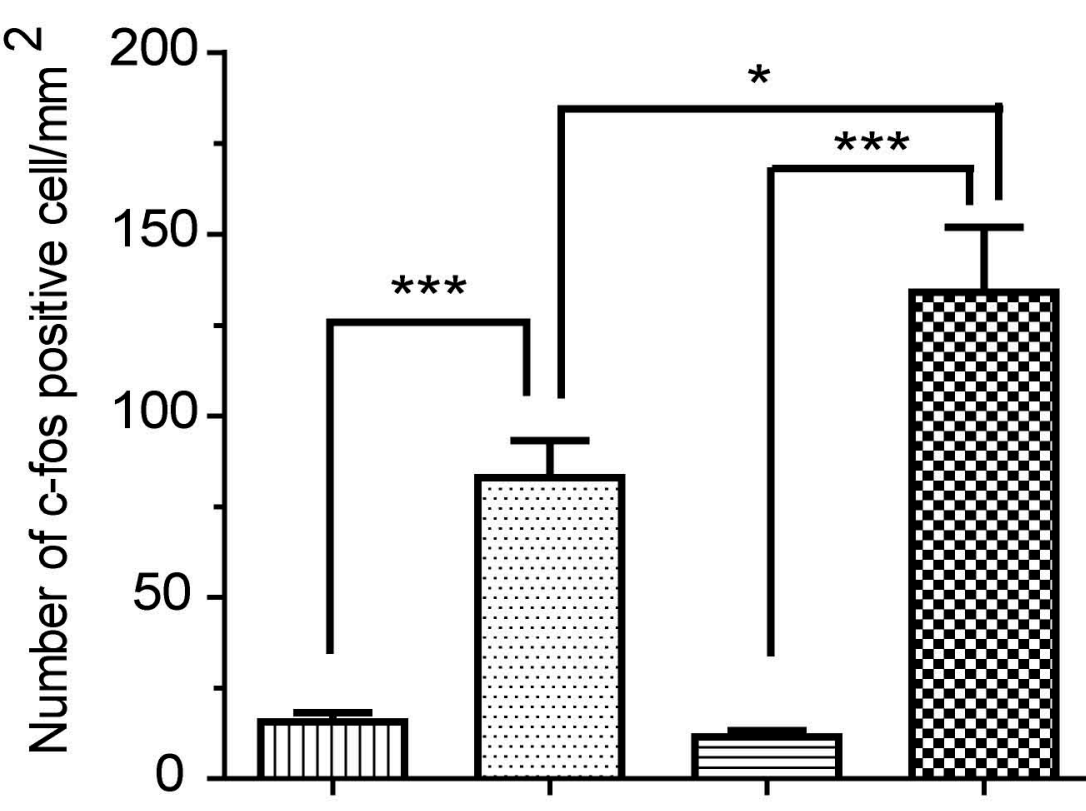

D
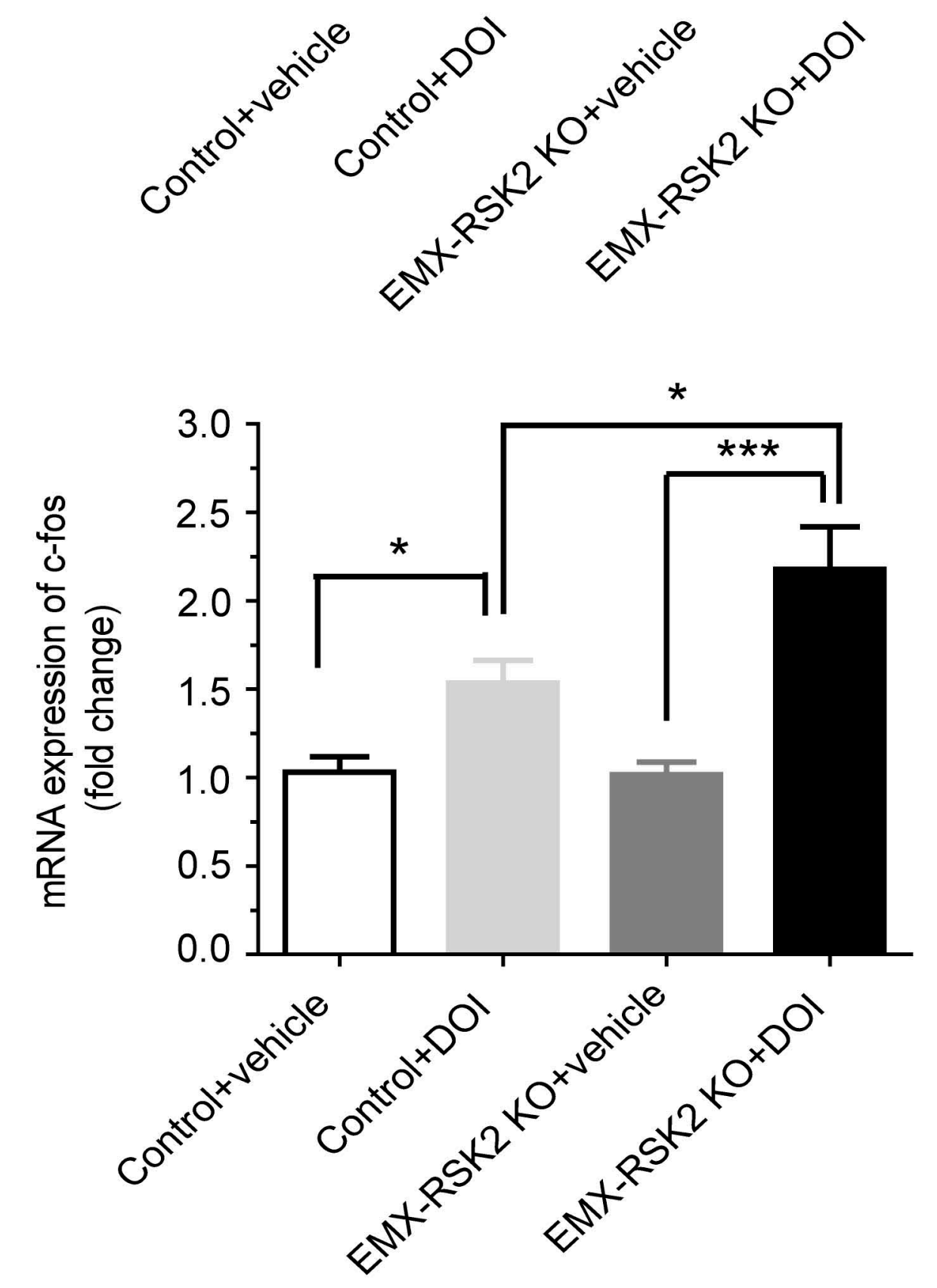

E

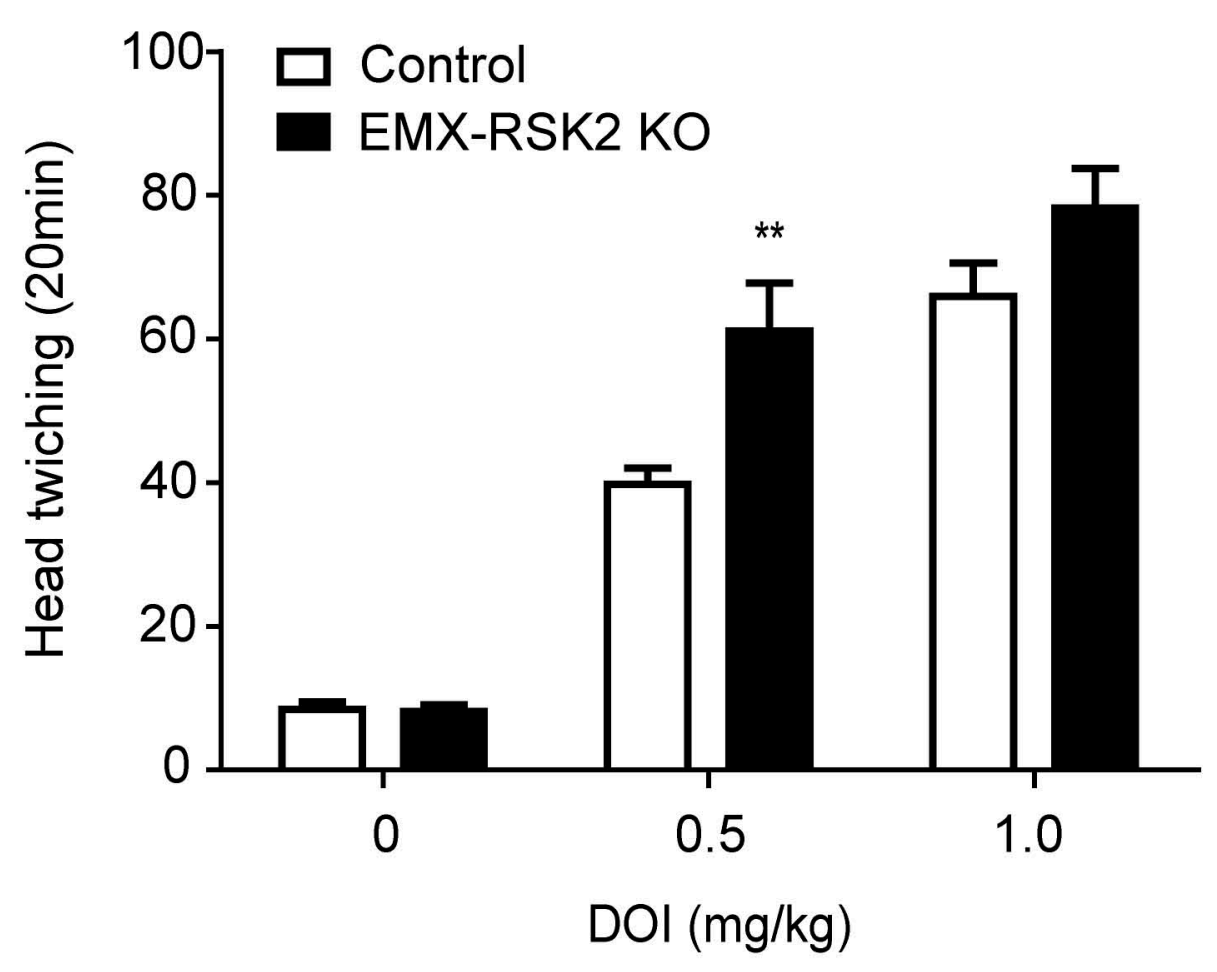

$\mathbf{F}$

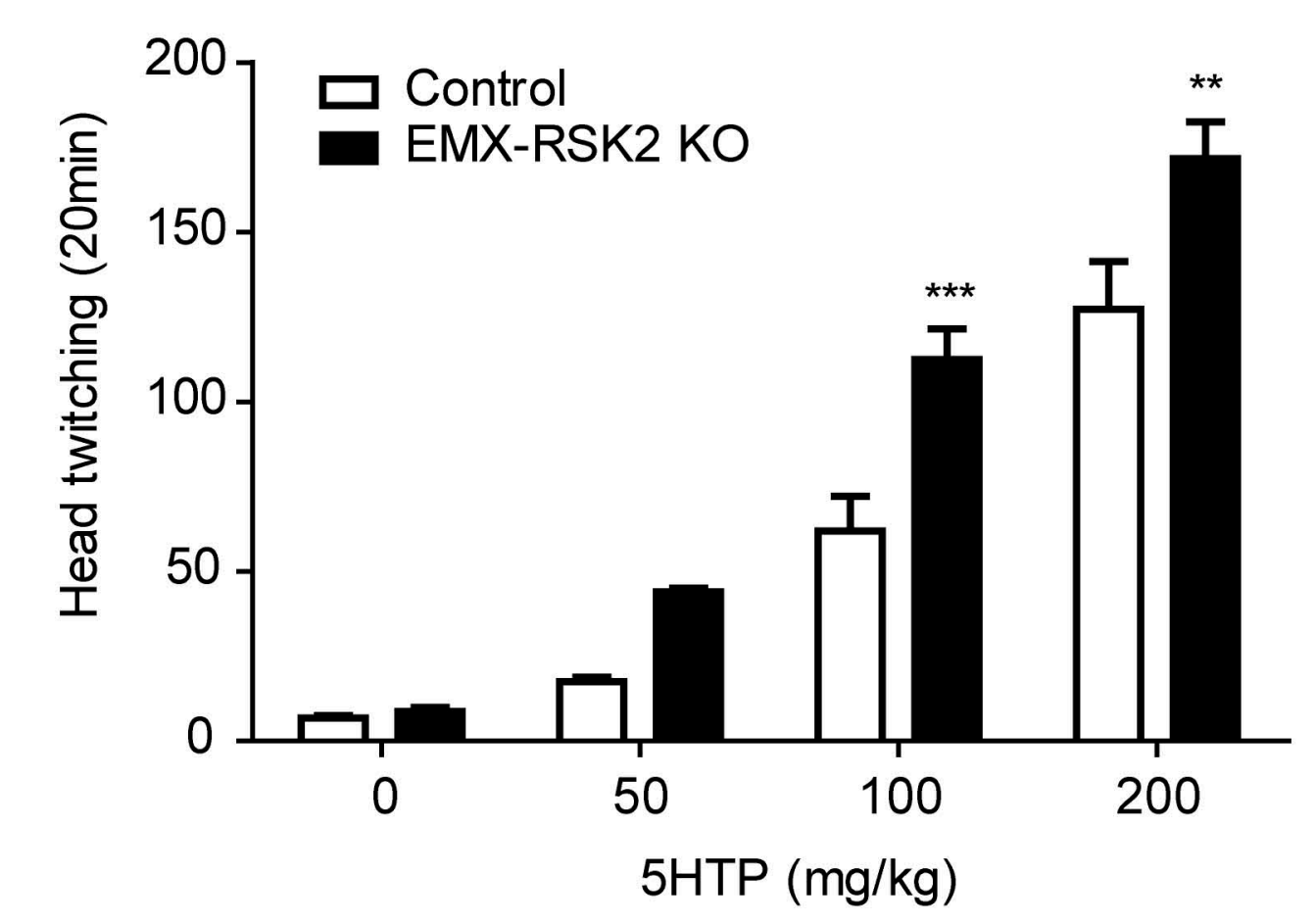




\section{Figure 6}

A

Pair-1

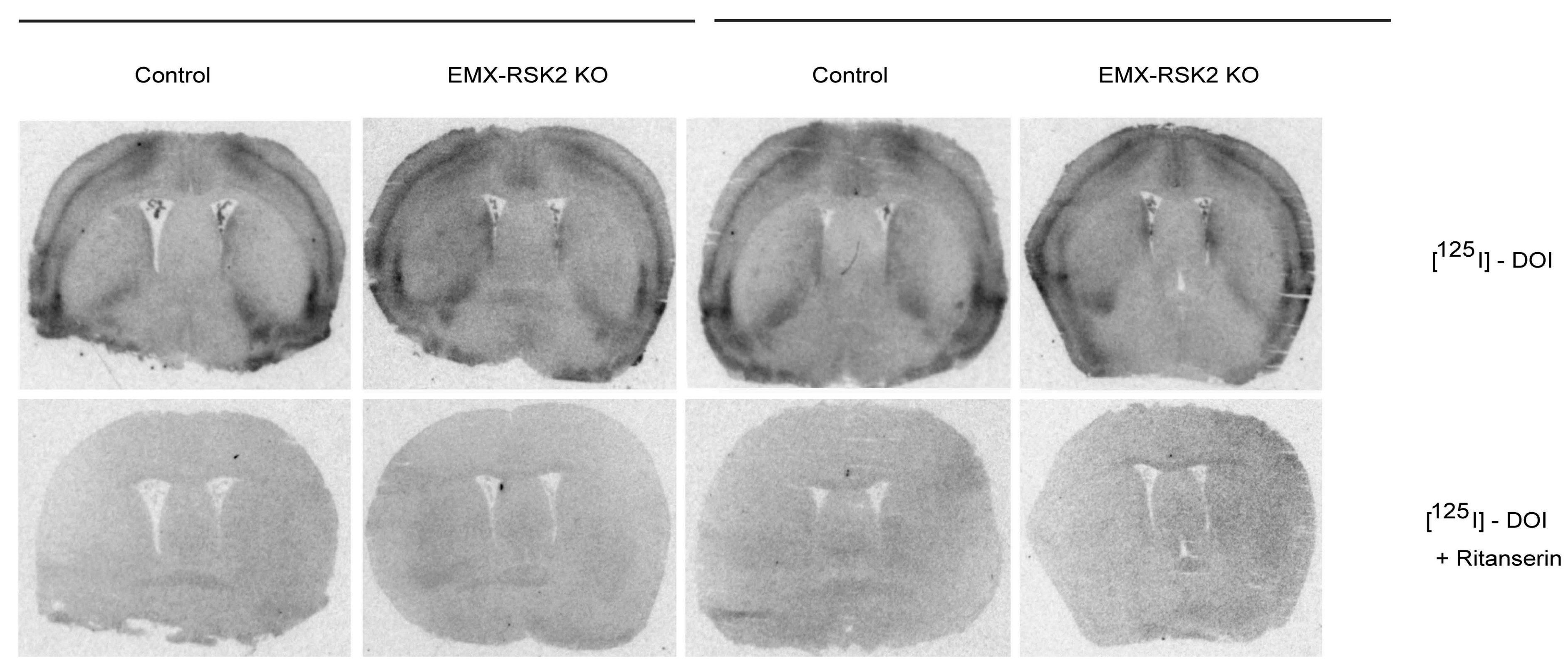

B

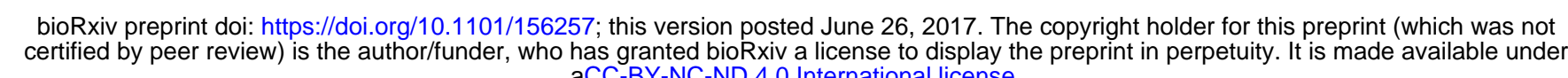
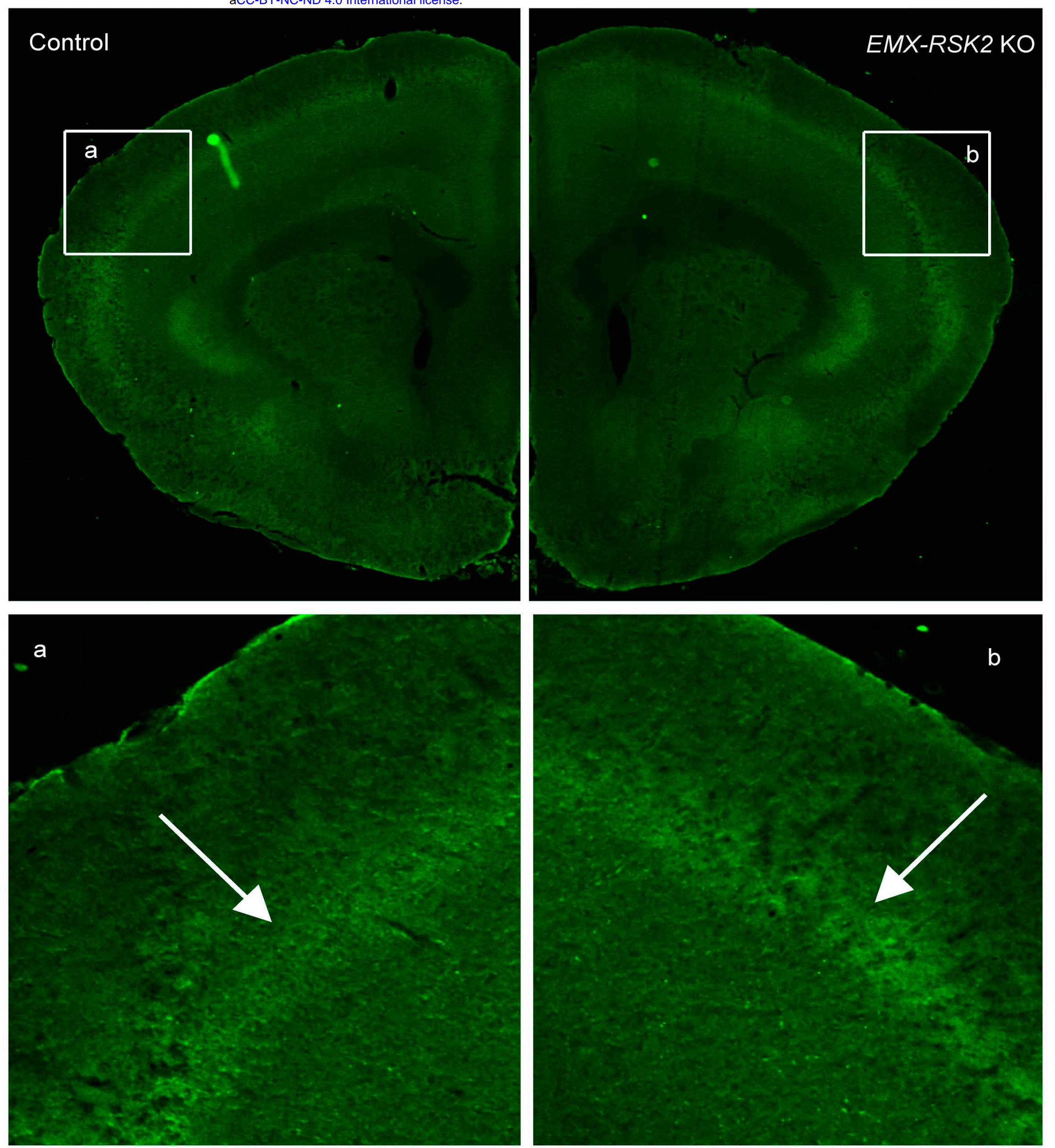

C

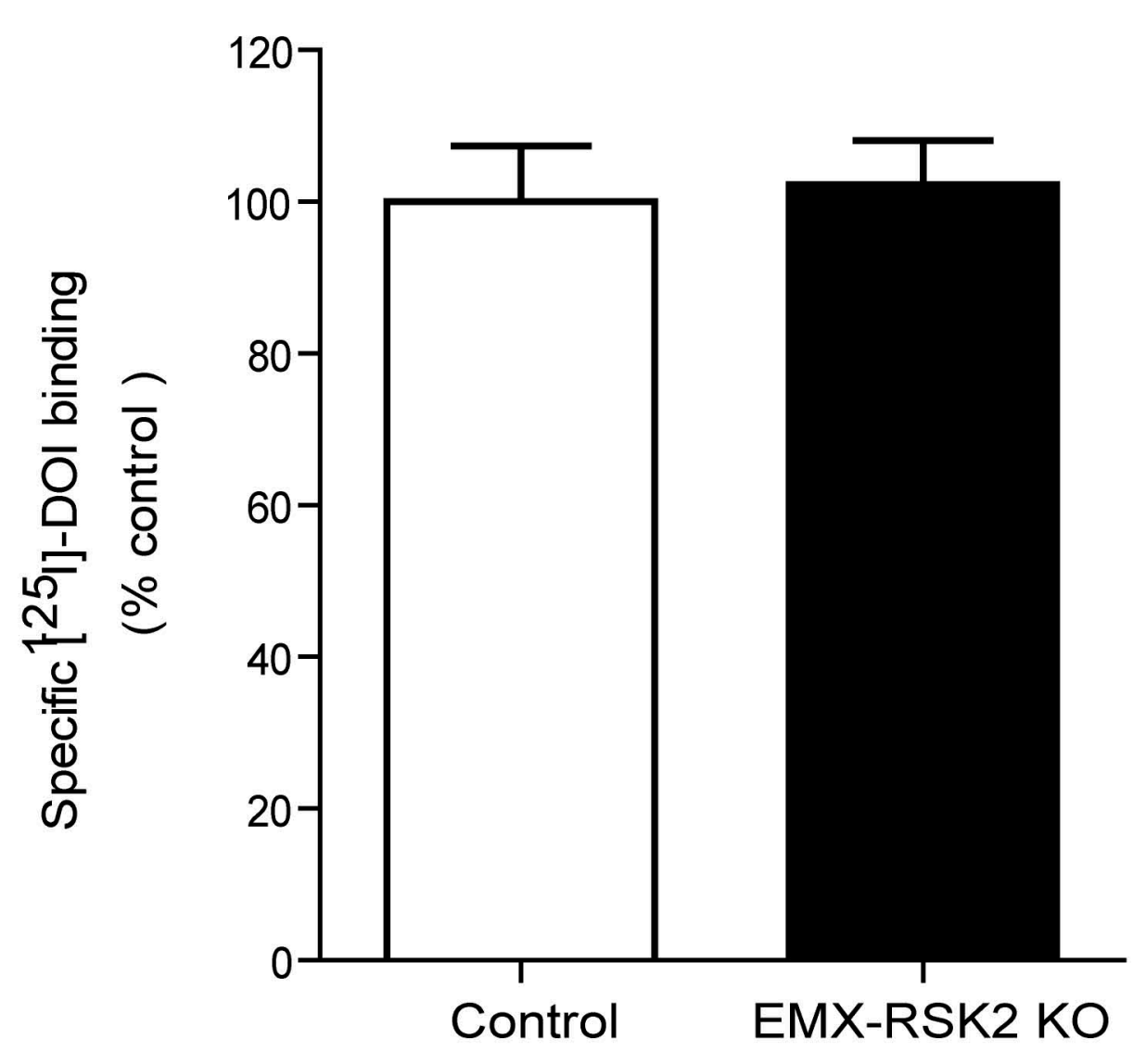

D

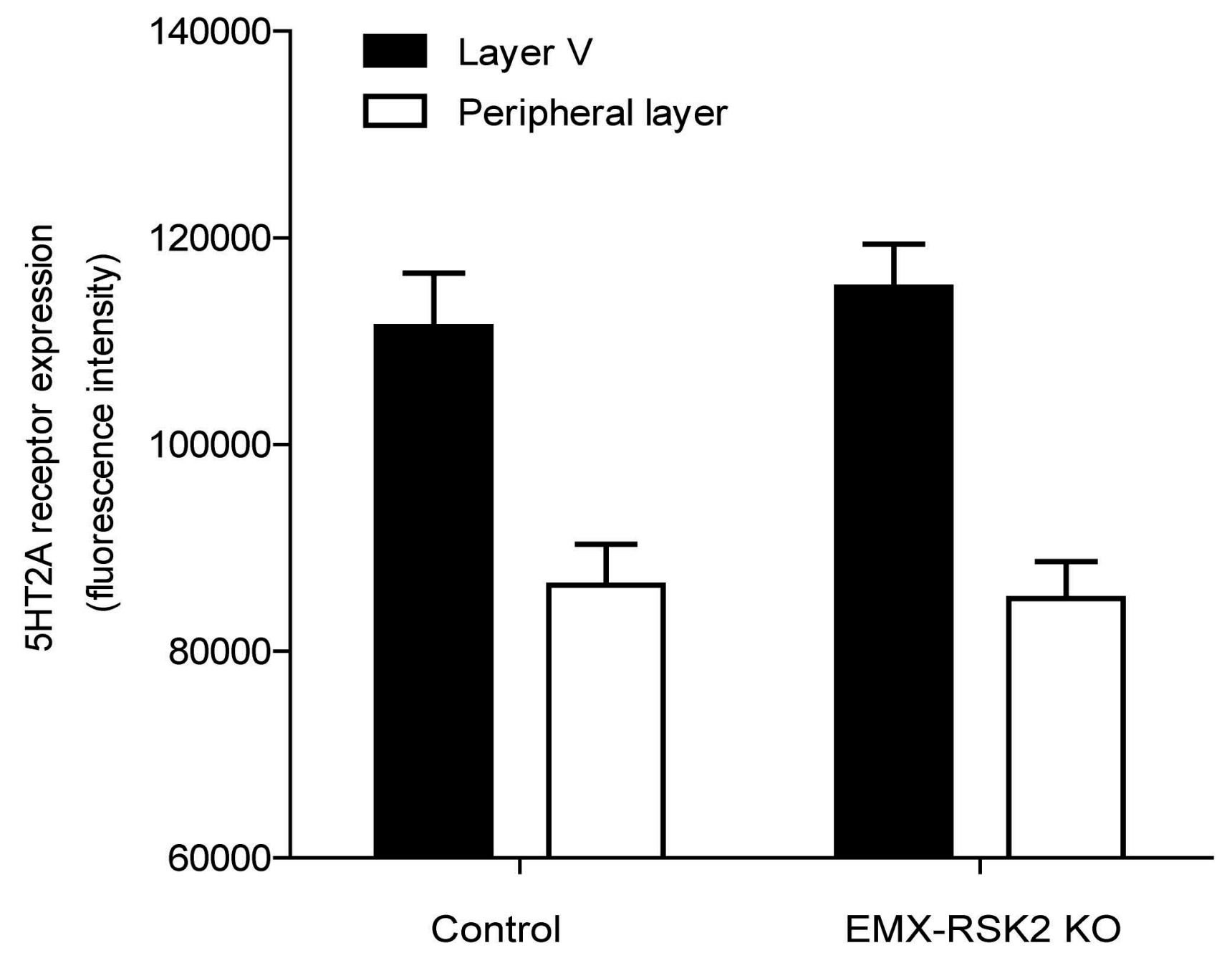

